\title{
EL ARCHIVO PARROQUIAL DE AYORA: FONDOS MANUSCRITOS*
}

\author{
Vicente Pons Alos
}

\section{INTRODUCCION}

La importancia de los archivos parroquiales para la historia local y general está sobradamente probada, así como su interés en distintos campos de investigación: historia eclesiástica, demografía, historia del arte, economía, estudios sociales e historia de las mentalidades (1). Fernández Catón ve en ellos una fuente imprescindible para el estudio de muchas realidades hasta ahora olvidadas; la historia y la misma iglesia, creadoras a lo largo de los siglos de esa fuente imprescindible, nos urgen a que cuidemos este patrimonio. De ahí la nacesidad de que la iglesia tome conciencia de esto y acuda, cuando todavía hay tiempo, a remediar los males que sobre él pueden venir (2).

* Aunque el presente trabajo desborda el marco cronológico de la revista, hemos creído de interés su inclusión en la misma al estar vinculada su temática con el mundo de la Paleografía y Archivistica.

(1) Sobre valoración histórica de los archivos parroquiales véase: FABREGA GRAU, A., LOS archivos eclesiásticos y la investigación histórica, en uLos archivos de la lglesia en Españan (León, 1978), págs. 37-55. REPRESA ROORIGUEZ, A., Valoración histórica de los archivos parroquiales, en "Los archivos de la Iglesia en España» (León, 1978), pág. 91-108. RUBIO MERINO, P., Tipología documental en los archivos parroquiales, en "Archivistica: Estudios básicos" (Sevilla, 1981), págs. 211-236: TRENCHS ODENA, J., Notes entorn de la Tipología dels documents dels arxius comarcals, en «l Assemblea d'História de la Ribera” (Nalencia, 1981), págs. 14-18.

(2) Cfr. FERNANDEZ CATON, J. M.*, Los archivos parroquiales, en aLos archivos de la Iglesia en España" (León, 1978) pág. 143. 
No obstante y pese a los últimos esfuerzos, varios problemas siguen caracterizando estos archivos. Por una parte su escasez, pues en un $75 \%$ han desaparecido a causa de las distintas contiendas civiles, no siendo de desechar los robos, pérdidas y expurgos; por otra, la mayoría de ellos permanecen sin organizar y sin inventariar, lo que dificulta el trabajo del historiador, que encuentra difícil el acceso a los fondos parroquiales, dada la ausencia de un especialista que facilite la investigación (3).

Intentando romper esta problemática recogemos en este trabajo (4) el inventario de los fondos manuscritos del archivo parroquial de Ayora (5), dado el volumen e importancia de su documentación, lo que le hace ser uno de los archivos parroquiales más completos de la diócesis (6). Nos han servido de orientación los últimos trabajos publicados sobre estos archivos (7) y las disposiciones de la Asociación Nacional de archiveros eclesiásticos (8).

(3) Cfr. FERNANDEZ CATON, J. M. ${ }^{\circledR}$, Problemática de los archivos parroquiales españoles, en "Actas de las I Jornadas de Metodología aplicada a las ciencias Históricas. Paleografía y Archivística "Vol. V (Santiago de Compostela, 1976), págs. 51-56.

(4) Agradecemos la dirección del mismo al Dr. D. José Trenchs Odena, la colaboración y ayuda de los sacerdotes de Ayora D. Miguel Díaz Valle y D. José Verdeguer García, y de la Dr. ${ }^{a}$ D. ${ }^{\mathrm{z}}$ M. ${ }^{\mathrm{a}}$ Milagros Cárcel Ortí.

(5) En trabajo aparte catalogamos los fondos impresos.

(6) Cfr. Guía de la lglesia en la Diócesis de Valencia. Valencia, 1963. ARGENTE VIDAL, J., EI archivo parroquia/ de Alcúdia de Crespins (ejemplar mecanografiado). MORENO ROYO, J. M. ${ }^{a}$, El archivo parroquial de San Juan Bautista de Manises, en el Congres d'História del Pais Valencia" I Nalencia, 1973), págs. 491-508. TORRES FAUS, F., El arxiu parroquial de l'esglesia de Nostra Senyora de l'Assumpcio de Carcaixent (ejemplar mecanografiado). TORRES FAUS, F. et al., Introducció a les fonts documentals de la Ribera Afta, en "I Assemblea d'História de la Ribera" Nalencia, 1981), págs. 185-208. Distintos artículos en “ll Assemblea d'História de la Ribera" (Algemesi, 1981). En prensa.

(7) Cfr. TRENCHS ODENA, J., op. cit; ibid. L'arxiu parroquial de Villalonga del Camp, en "Primeres Jornades d'investigació d'els arxius del Camp de Tarragona" (Tarragona, 1979), págs. 54-59. CARCEL ORTI, M." M.-TRENCHS ODENA, J., Las visitas pastorales de Cataluña, Valencia y Baleares. “Archiva Ecclesiae” XXII-XXIII (1979-1980), págs. 491-500. CARCEL ORTI, M. ", M.-TRENCHS ODENA, J., Las visitas pastorales, en "ll Assemblea d'História de la Ribera" (Algemesi-1981). En prensa. RUBIO MERINO, P. Op. cit., y distintos artículos en "Los archivos de la Iglesia en España" (León, 1978); en las "Actas de las । Jornadas de Metodología aplicada de las ciencias históricas. Paleografía y Archivistica" $V$ (Santiago de Compostela, 1976); “Primeres Jornades d'investigació d'els arxius del Camp de Tarragona (Tarragona, 1979), págs. 17-77; SALA Y VILA, A., Els arxius parroquials, la seua importancia, classificació $i$ catalogació. Manresa, 1912; CAP DE VILLA, El archivo parroquial y su ordenación. Estudio y normas prácticas para ordenar, catalogar $y$ conservar archivos parroquiales (TarragonaBarcelona, 1926).

(8) Cfr. Reg/amento de los archivos eclesiásticos españoles, en "Los archivos de la Iglesia en España" (León, 1978), págs. 221-239. 


\section{EVOLUCION POLITICA DEL SEÑORIO DE AYORA}

Por el tratado de Cazola (1179) y más tarde el de Almizra (1244), se delimitaba la frontera entre Aragón y Castilla, en una línea marcada por los lugares de Ayora, Biar y Aguas de Busot (9). Ayora, en el marco del reino de Murcia, fue repoblada por Castellanos (10) y perteneció al reino de Castilla hasta 1281 , fecha en que Alfonso X prometió a Pedro III los castillos de su valle (11).

A pesar de que la frontera entre Castilla y Aragón no quedó totalmente fijada hasta el acuerdo de Elche (1305) (12), a partir de 1281 el valle de Ayora pasó definitivamente a la corona aragonesa, como lo prueban varias disposiciones de Pedro III a los moradores de los pueblos del valle (13) y la aparición de Ayora en 1292 entre los lugares que pagan impuesto de cena (14).

Del período castellano queda un privilegio de franqueza a fuero de Cuenca concedido por Alfonso $X$ a Ayora en 1271 (15), así como la

(9) Tratado de Almizra en 26 de marzo de 1244 (Cfr. HUICI MIRANDA, A., CABANES PECOURT, M." D., Documentos de Jaime / de Aragón (1237-1250). Il. Valencia, 1976, págs. 176-177; GUAL CAMARENA, M., Precedentes de la Reconquista Valenciana. Valencia, 1953, pág. 205 y ss.; TORRES FONTES, J., La delimitación del sudeste peninsular. Murcia, 1950; ESTAL, J. M. del, Alicante en la política territorial de los dos Jaimes de Aragón, en «X Congreso de Historia de la corona de Aragón» (Zaragoza, 1980), págs. 65-79.

(10) Cfr. SANCHIS GUARNER, M., El reino autónomo de Valencia, «HISTORIA 16" (1976), VIII, pág. 83.

(11) 1281, marzo, 27. Vistas de Campillo: Archivo de la Corona de Aragón, Reg. Cancillería 47, fol. 103 v. ${ }^{\circ}-107 \mathrm{v} .^{\circ}$ (Cfr. MARTINEZ FERRANDO, J. E., Catálogo de la documentacion relativa al antiguo reino de Valencia en el Archivo de la Corona de Aragón. Il. Pedro II (1276-1285). Madrid, 1934, n. $.^{\circ} 1268,1269,1270$; TORRES FONTES, J., Op. cit, págs. 17-18; MARTINEZ AZORIN, E., Fechas históricas de la noble villa de Ayora. Almansa, 1921, pág. 14.

(12) Por el acuerdo de Elche $(1305$, marzo, 19) quedaba fijada la frontera entre el término de Caudete y Almansa, y entre Jumilla y Hellín hasta el Segura, en el término de Cieza. Se segregaba así de la conquista de Alfonso $X$ todo el valle de Ayora, del cual ya había hecho donación anteriormente en las Vistas de Campillo a Pedro Ill de Aragón (Cfr. TORRES FONTES, J., op. cit., págs. 17-18).

(13) En 21 de mayo de 1281, Pedro III ordena a los habitantes del valle de Ayora reconozcan por alcaide de los castillos del mismo a Juan Pérez de Ayerbe (Cfr. A.C.A. Reg. Cancilleria 49, fol. $88 v^{\circ}$ ). En 28 de noviembre del mismo año Pedrolll envía una carta al adelantado mayor de Castilla para que sean elegidas tres personas que decidan sobre los lindes de Ayora y Almansa (Cfr. A.C.A. Reg. Cancilleria 50, fol. 200 v. $)$. Posteriormente distintos nombramientos de alcaides en 1282, 1286, 1289 y 1290 (Cfr. MARTINEZ FERRANDO, J. E., op. cit., n. ${ }^{\circ}$ 1.469; GALLOFRE GUINOVART, Documentos de Alfonso III de Aragón (Nalencia, 1968) n. 210 1.273-1.477).

(14) Cfr. MATEU Y LLOPIS. F., Colecta de la cena en el Reino de Valencia en 1292-1295, B.S.C.C. XLVI (1960), pág. 220.

(15) 1271 , diciembre, 9. Murcia. Privilegio rodado por el que Alfonso $X$ concede a Ayora las franquezas del fuero de Cuenca (Archivo Municipal de Ayora, Pergamino n. ${ }^{\circ} 1$ ). En prensa. 
mención a otros privilegios de la misma época, que no se conservan (16). Tras pasar a Aragón, Alfonso III (1285-1291) le concedía en 1290 un privilegio de franqueza, haciéndole libre de peajes, portazgos y herbajes, permitiendole poder vedar sus bovalares y dehesas y celebrar un mercado todos los jueves (17). En 1321, Jaime II (1291-1327) concedía permiso para que se celebrara en el lugar una feria los 15 primeros dias de septiembre (18).

En 1328, el lugar pertenecía por donación de Alfonso IV (1327-1336) a su mujer Leonor de Castilla, salvo un violario perteneciente a Bernardo de Sarriá, quien parece había sido durante un corto período de tiempo señor del valle de Ayora (19). Leonor de Castilla, viendo que se despoblaba el valle de musulmanes otorgó nuevos capítulos de población en 1336 (20), fecha en que seguía siendo señora de la villa (21). Después pasó a su hijo Fernando y de él a Pedro IV (1336-1387), quien en 1364 la dio a su pariente Alfonso, conde de Ribagorza y Denia, marqués de Villena y duque de Gandia (22). Tras su muerte en 1412, le sucedió su hijo, del mismo nombre, en todos sus estados, salvo en el de Villena. Al morir éste sin sucesión en 1422, sus señoríos revierten a la corona (23).

Alfonso V (1416-1458) hizo donación de Ayora en 1429 a su hermano Juan, rey de Navarra (24), quien a su vez la dará en 1431 a Diego Gómez de Sandoval, conde de Castro (25). En 1452 la poseía Isabel Lladró por pago de la dote de su esposo, el conde de Castro (26); de la cual pasó a

(16) Cfr. MARTINEZ AZORIN, E., Fechas historicas de la noble villa de Ayora (AImansa, 1921); Razón y relación de los señores que han sido de esta villa de Ayora desde el rey Miramolin de Marruecos (Archivo Municipal de Ayora, Actas 1729-1731, pág. 98 r-99 v.); A.H.N. Osuna, Leg. 2.280, vol. I, fol. 133-154.

(17) 1290, agosto, 23 (Archivo Municipal de Ayora. Pergamino n. 2 ; A.C.A. Reg. Cancilleria, 83 , fol. 81).

(18) 1321, mayo, 4. Valencia (A.H.N. Osuna, Carpeta 182, Pergamino n.o 2).

(19) Cfr. CHABAS, R., Aprobación de las donaciones hechas por Bernardo de Sarria al infante D. Pedro. "El Archivo" IV (Valencia, 1890), págs. 318-323.

(20) 1336, julio, 16 (A.H.N. Osuna, Carpeta 75. Pergamino n. ${ }^{\circ} 17$ ).

(21) 1336, julio, 16. Albarracín (Cfr. OLMOS CANELDA, E., Pergaminos de la catedra/ de Valencia. Valencia, 1961. Pergamino n. 1489).

(22) 1364, marzo, 22. Cullera (A.H.N. Osuna. Leg. 1931-10').

(23) Cfr. CONDE DELGADO DE MOLINA, R, El archivo de los duques reales de Gandía. "I Congreso de Historia del País Valenciano" (Valencia, 1973), págs. 429-437; Privilegios y memorias de los señores que han sido de esta villa de Ayora... (A.H.N. Osuna. Leg, 2.280, vol. I, fols. 135-154).

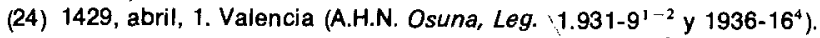

(25) 1431, marzo, 8. Lérida (A.H.N. Osuna. Leg. 1931-5, 1936-16 y 1937-14; A.R.V. Real Cancilleria, 495).

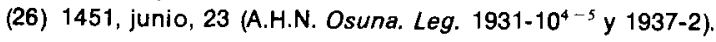


su hermano Baltasar Lladró (27) y a su muerte, su mujer Aldonza de Rocafull, como curadora de su hijo Ramón Lladró, la vendió en 1491 a Rodrigo de Mendoza, marqués de Cenete (28).

Con Rodrigo de Mendoza, señor de Ayora y de las baronías de Alberique, Alasquer, Alcoser y Gavarda, heredadas de su padre el cardenal Mendoza, se abre un período de esplendor de la casa, reforzado con el matrimonio de su hija Mencia con el duque de Calabría. A la muerte de la duquesa de Calabría, le sucederá su hermana María, quien contraerá matrimonio con Diego Hurtado de Mendoza, hijo del duque del Infantado, título al que más tarde su unirán los de Pastrana, Lerma y Osuna, señores de Ayora hasta la abolición del régimen señorial en el siglo XIX (29).

\section{EL MARCO ECLESIASTICO-RELIGIOSO}

El 11 de noviembre de 1266, Alfonso $X$ señalaba en Sevilla - después de crearse la diócesis de Cartagena en 1250 - los términos que comprendia: Alicante con su término, asi como parte con término de la tierra del rey de Aragón, Petrel, Sax e Villena e la tierra de Don Manuel, nuestro hermano, como parte con la tierra del rey de Aragón, e del val de Ayora hasta Confruentes (30). De esta forma dentro del reino de Valencia y en el obispado de Cartagena se erigían, amén del arciprestazgo de Orihuela en 1281, los vicariatos de Alicante, Elche, Caudete y el de Ayora, que comprendía la villa y los lugares de Cofrentes, Jarafuel, Palazuelos, Zarra, Teresa y Jalance. Cada uno de estos vicariatos, con su notario mayor y portero, facilitaban la resolución de los casos más urgentes, de los asuntos matrimoniales y contribuian a la mejor organización de la diócesis y al cumplimiento de los decretos sinodales (31).

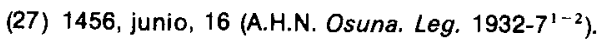

(28) Cfr. A.H.N. Osuna. Leg. 1932-15 a 18, 1937-10, 2280-1; Leg. 1933-4 ${ }^{1-3}, 1937-13$ y 2225-3 (1491, diciembre, 17).

(29) Rodrigo de Mendoza, marqués de Cenete, casó con María de Fonseca, además de su hijo primogénito que murió pequeño tuvo tres hijas: Mencia de Mendoza, casó en segundas nupcias con el duque de Calabria (Cfr. ALMELA, F., El duc de Calabria i la sua cort. Valencia, 1958), y tras su muerte sin sucesión ( $\$ 1555)$ le heredó su hermana María ( +1580$)$ que contrajo matrimonio con Diego Hurtado de Mendoza. Con el hijo de ambos: Iñigo López de Mendoza entró en la casa el ducado del Infantado (Cfr. GUTIERREZ CORONEL, D., Crónica histórica y genealógica de la casa de Mendoza (1771-Cuenca, 1946), 2 vol.).

(30) Cfr. DIAZ CASSOU, P., Serie de obispos de Cartagena: sus hechos y su tiempo. Madrid, 1895; NAVARRO BOTELLA, J. M. ${ }^{a}$, El primer sinodo de Orihuela. 1597. Alicante, 1979, págs. 53-54; TORRES FONTES, J., El obispado de Cartagena en el siglo XIII. "HISPANIA" XIII (1953), págs. 339-400, 515-532.

(31) Cfr. NAVARRO BOTELLA, J. M.", op. cit., pág. 53; VILAR, J. B., los siglos XIV y XV en Orihuela, Ill. Murcia, 1977, pág. $3 \overrightarrow{17}$. 
Desde un primer momento los problemas surgieron, ya que si bien los territorios de la gobernación de Orihuela y el valle de Ayora pertenecían en lo civil al reino de Valencia, eclesiásticamente dependían de Cartagena, vinculada a Castilla, con los consecuentes conflictos entre la diócesis de Valencia y la de Cartagena en razón de diezmos, rentas y otros asuntos propios de las iglesias del valle de Ayora (32). Sin embargo, será el cabildo de Orihuela quien propugne su separación de la sede arzobispal, a través de un largo proceso, jalonado en las siguientes etapas (33):

1. Prearciprestazgo de Orihuela (1250-1281).

2. Arciprestazgo (1281-1413). En 1281 Diego Martínez, obispo de Cartagena (1278-1301) elevó a arciprestal el templo de el Salvador y Santa María (34).

3. Colegiata (1413-1456). Benedicto XIII por bula de 13 de abril de 1413 erigió la arciprestal de Orihuela en colegiata, a petición del rey de Aragón y a pesar de las protestas del obispo de Cartagena (35). Precisamente un ayorino, muy vinculado al Papa Luna, Miguel Molsos (1370?-1431), ejerció un papel fundamental en esta concesión y en la posterior confirmación por Martín $V$ en 1419 (36), quien además le confirma en el cargo de primer pavordre de Orihuela, nombrándole su confesor y auditor de la Rota (37).

(32) 1308-1317 (A.C.V. Pergaminos 7422, 7424, 7468, 9494, 3016 en OLMOS CANELDA, E., Pergaminos de la Catedra/ de Valencia, Valencia, 1961); 1281, agosto, 17. Lérida. Orden a los alcaides del valle de Ayora de que confisquen los frutos que corresponden a las iglesias del mismo hasta que se solucionen los problemas entre el obispado de Cartagena y el de Valencia (A.C.A. Reg. Cancilleria 50, fol. 157); 1281, diciembre, 5. Alzira. Carta a Alfonso X sobre las diferencias entre los obispos de Cartagena y Valencia por las iglesias del valle de Ayora (A.C.A. Reg. Cancilleria 50, fol. 205); 1282-1285. Mandatos del infante al alcaide del valle de Ayora de que se mantenga al arcediano de Valencia en su derecho de percibir los réditos eclesiásticos del valle, a pesar de la oposición del obispo de Cartagena (A.C.A. Reg. Cancillería. 59 - 61 - 49 56, fol. 101, v-192 - 89 - 20).

(33) Cfr. BELLOT, P., Anales de Orihuela (s. XIV-XVI). Orihuela, 1956; RUFINO GEA, J., EI pleito del obispado 1383-1564. Orihuela, 1900; NAVARRO BOTELLA, J. M." op. cit., págs. 72-75; VILAR, J. B., op. cit., págs. 369-387.

(34) Cfr. EUBEL, C., Hierarchia Catholica. I. Monasterii, 1913, pág. 168.

(35) Cfr. Archivo Catedral de Orihuela, Armario IX. Leg. I. Pergamino 1.

(36) Cfr. 1419, abril, 19. Florencia (A.C.O. Arm. IX, Leg. I. Pergamino 11).

(37) Cfr. Diccionario de Historia eclesiástica de España. Madrid, 1972, págs. 1.836 y ss.; MARTINEZ AZORIN, E., Fechas históricas de la noble villa de Ayora. Almansa, 1921, págs. 11, 37, 39; ibid. Historia de la ilustre villa de Ayora y los pueblos de su valle. Almansa, 1929, pág. 93; VERDEGUER GARCIA, J., Migue/ Molsos: 550 años de su muerte (1431-1981). Ayora, 1981; VIDAL TUR, G., Un obispado español, e/ de Orihue/a-Alicante. Alicante, 1962. 
4. Vicariato (1456-1510). Eugenio IV le concedió un vicariato general independiente de Murcia.

5. Catedral (1510-1564). Julio II por bula de 27 de abril de 1510 la erigió en catedral, a instancias de Fernando el Católico.

6. Diócesis (1564). Pio IV el 14 de julio creó definitivamente la diócesis de Orihuela, sufragánea de la de Valencia.

La organización de vicarías foráneas se mantuvo con pocos cambios después de la incorporación de Ayora a la diócesis de Orihuela hasta el concordato de 1851, en que se suprimieron estas vicarías y se crearon 8 arciprestazgos, entre ellos el de Ayora.

Finalmente el 13 de marzo de 1954 las parroquias de Villena, Sax y la filial de La Encina en la provincia de Alicante, pasaron de la diócesis de Cartagena a la de Orihuela-Alicante y ésta cedió el arciprestazgo de Ayora a Valencia (38).

\section{EL ARCHIVO PARROQUIAL}

El archivo parroquial de Ayora está ubicado en la Iglesia arciprestal de Nuestra Señora de la Asunción. Su importancia viene subrayada, además de por el volumen de su documentación (39), por la continuidad y variedad de sus series (40) y por el papel desempeñado por la parroquia a través de su historia, papel marcado no sólo por su carácter fronterizo y preeminencia eclesiástica, sino también por otros factores de indole económico y social, así como propiamente religiosos (41).

(38) Cfr. CASTELL MAIQUES, V., La provincia eclesiästica valentina: Precedentes yjustificación histórica. A.C.C.V. (1970), págs. 106-110.

(39) 840 libros, 80 cajas de documentos en cuadernos o pliegos y 400 volúmenes impresos que se catalogan aparte, de entre ellos varios incunables.

(40) Contribuye a la importancia del archivo parroquial la pérdida casi total del municipal, salvo 5 pergaminos (1271-1613) y la serie de Actas Municipales (1715-...). El resto de la documentación pertenece a los siglos $X I X-X X$, ya que se destruyó casi totalmente con la guerra de Sucesión (1707) (Cfr., MARTINEZ AZORIN, E., Fechas... pág. 24) y las posteriores guerras carlistas (1839). No obstante Aybra puede considerarse afortunada al conservar el archivo parroquial, los protocolos notariales - parte en el parroquial y parte en el A.R.V.- - la documentación señorial de la Casa del Infantado en la sección de Osuna del A.H.N. y la de los conventos de la Encarnación y Santo Dómingo en la sección Clero del A.R.V.

(41) Pestes, sequías, plagas y una ingente cantidad de misas perpetuas, legados, capellanías y mandas pias llevaban al aumento de la religiosidad y sus manifestaciones, a la cabeza de las cuales se encuentra la del "Angel de Ayora". El milagro cuenta como en 1392, hallándose el valle bajo las consecuencias de la Peste, se le apareció un ángel a la hornera "Liñanan que se dirigia desde Ayora a Jarafuel, el cual le encomendó una rogativa, tras la cual cesó la peste (Cfr. MARTINEZ AZORIN, E., Memorias de la aparición de un ángel en la villa de Ayora. Almansa, 1922; CARCEL ORTI, V., Un folleto del siglo XVIII sobre el milagro de Ayora. "Levante» suplemento "Valencia" (30-III-1963)). 
Estos factores hicieron de Ayora el núcleo más importante dentro del valle (42), con abundante número de miembros del estamento eclesiástico (43), con el desarrollo de sectores sociales privilegiados de importante papel en el gobierno de la villa (44) - a pesar de ser lugar de señorio (45)-, con numerosas obras de interés artístico (46), un sin fin

(42) Sobre el papel de Ayora conviene destacar el hecho de que es el punto de más población del valle, su notaria, otros elementos de atracción, testificados por el hecho de encontrar infínidad de legados piadosos a la parroquia de la villa y el hallazgo de varios "Cabreus" de los vecinos de los distintos pueblos del valle.

(43) En 1567 había 28 plazas con organista y sacristán. Tras reducirse el número de plazas a finales de siglo, se tuvo que volver a aumentar debido a la gran cantidad de misas que quedaban sin decir. En 1612 habia 27 plazas, que se redujeron en 1663 a 22 para volver a aumentarse a 24 diez años más tarde. El número permaneció estable, disminuyendo ligeramente en el siglo $\mathrm{X} \mid \mathrm{X}$ para quedarse en 6 plazas en 1907 y actualmente en 2.

El capítulo estaba compuesto por un vicario y varios presbiteros que ocupaban los cargos de racional, archivero, síndico, sochantre, conventualero, animero, claviculario, jueces contadores, mayordomo de San Pedro y enfermos, revestidores, mayordomo de Nuestra Señora del Espino, comisario y a veces el de colectores y notario. Ayudaban al servicio, además del sacristán mayor que debía ser presbítero, dos sacristanes menores, organista, campaneros, infantillos y ordinario.

Los cargos eran renovados el 21 de diciembre dè cada año, siendo la elección hecha por el clero, salvo en el caso de los sacristanes, organista, campaneros e infantillos, cargos sobre los cuales el señor de la villa tenía derecho de "presentación". Desde 1559 y 1573 respectivamente se sumaba al clero secular los religiosos del Convento de la Encarnación (dominicos) y de San Antonio de Padua (franciscanos) por iniciativa del duque de Calabria y particulares.

(44) Apoya esto la existencia de varias familias (Ruizes de Asin, Portillas, Alonsos, Briones, Pérez Pastor...) que monopolizaban los cargos en el gobierno de la ciudad, además de ser los titulares de fundaciones, capellanías y otros legados piadosos y gozar de importantes privilegios (indulgencias, miembros entre el clero de la villa, derecho a sepultura en los vasos de la iglesia, presidencia de gremios y cofradías...). Eran miembros de profesiones liberales (notarios, médicos, farmacéuticos, presbíteros...), labradores acomodados que dirigían y poseían las principales regalías y rentas del señor (hornos, carnicería, almacera, herrería...).

El consejo de la ciudad estaba integrado por un procu rador general, representante del señor, los regentes o consejeros y de entre ellos un justicia, un baile mayor, un baile menor, dos jurados, almotacén, síndico y varios notarios del procurador general, del justicia y de la sala respectivamente.

De la fuerza de este grupo nos habla un memorial que elevaron en 1601 al duque del Infantado (Cfr. A.H.N. Osuna. Leg. 1923-2).

(45) En 1618 el duque del Infantado poseía las regalias de hornos, derecho de peaje, saca de madera, pescatería, bodeguilla, derecho de los herbajes, tercios diezmos menudos, derecho de morabati, tercio-diezmo del ganado, tercio-diezmo del vino, del carnaje, de la lana, queso y leche; derecho de la quinta casa, las carnicerías, molinos, batanes y tintes, granero; censos que responde la villa; casas de la Vega, Terrazgo de la Vega y demás tierras que fueron de los moros; penas y quintas, leña y bellotas, penas de cámara, derechos de presentación de varios cargos para la parroquia... (Cfr. A.H.N. Osuna, Leg. 1936-5 ${ }^{1-2}$ ). Sin embargo, ya desde el siglo XVI el absentismo es total, arrendándose todos los derechos a una élite de la ciudad.

(46) A pesar del saqueo a la iglesia durante el 36, los restos artísticos que se conservan nos hablan del importante volumen de obras de arte. Se conservan entre otras obras, además de la 
de ermitas dispersas alrededor del casco urbano y de su término (47) y sobre todo un voluminoso archivo, resultado de la importante actividad de esta parroquia.

El emplazamiento del archivo no ha sido siempre el mismo. Suponemos que en un principio estaria en la iglesia antigua (48), aunque la documentación que conservamos en casi su totalidad sea del período posterior a la titularidad de la misma. Los libros de Visita más antiguos lo sitúan en la sacristía de la iglesia o en una habitación inmediata (49), hasta que en el siglo XVIII se trasladó a su emplazamiento actual (50),

iglesia antigua (s. XIII), muestra del gótico primitivo valenciano y de la parroquial de la Asunción de importante fachada renacentista (1508-1595-1628); un retablo de Yáñez de la Almedina y otro de 1524 recientemente identificado por D. José Verdeguer García; obras de Vicente López y de la Escuela italiana... El esplendor artístico estuvo marcado en el XVI con el patronazgo de los duques de Calabria, resurgiendo en el XVIII a consecuencia del auge de la Burguesía local, cuya muestra más importante es la Capilla de la Comunión de la parroquial.

(47) Entre otras las ermitas de Santa Bárbara, San José, Santa Lucía, Santo Angel, Virgen del Rosario, San Roque, San Antonio, San Sebastián, La Aurora, Virgen de Gracia, de la Santa Cruz - Montemayor, San Benito, Santa Marta, Collado de San Juan, San José de Hoyas de Arona, San Juan de la Vega, San Calixto, Todos los Santos, San Miguel del Campo, San Pedro apóstol, Cristo de la Cañada... además de la parroquial, las capillas del Hospital, conventos de Santo Domingo y San Antonio y la iglesia antigua, también llamada de Santa Ana, San Blas, Santa Maria la mayor o de los altos. La erección de la mayoría de ellas en relación con advocaciones protectoras de pestes, epidemias, enfermedades, de la agricultura o ganadería o de determinados gremios y al mismo tiempo testimonio de la existencia del grupo de pequeña nobleza a que hemos hecho referencia.

(48) En 1577 se produce el traslado de altares y demás objetos desde la iglesia antigua a la de Santiago, después llamada de Nuestra $\mathrm{Sr}^{\mathrm{a}}$ de la Asunción.

(49) Hasta el siglo XVIII parece que el archivo estaba en una habitación inmediata a la sacristía según se desprende del orden en las visitas de la inspección del mismo, salvo los libros sacramentales que se hallaban junto con los óleos en el Baptisterio, siendo ordenado en varios mandatos de visitas que fuesen puestos junto con los demás.

(50) En 1742 el obispo de Orihuela Juan Elías Gómez de Terán manda se haga una nueva sacristía y archivo, dicho archivo quedará concluido en 1760 , año en que se ordena se abra una ventana en el mismo (A.P.A. Visitas, IV). La guerra de Su cesión debió hacer huella también en el archivo parroquial según se desprende de una nota en 1712: "Hemos hallado haberse llevado del archivo, sin culpa del clero, en el tiempo del saqueo, habiendo roto las paredes y arcas del depósito donde estaba dicho archivo, quitando censos de diferentes personas que no se pueden cargar..." (Cfr. A.P.A. Visitas, III, fol. 188 r.).

A las salas del archivo se accede por una escalera desde el Baptisterio. De ambas salas superpuestas $(4 \times 4 \mathrm{~m}$.), es la del segundo piso la que albergaba los fondos antiguos en un arca grande y varios armarios y estanterías, donde se guardaba junto con los libros y documentos, las rentas de la parroquia. En dicha sala, además de 2 arcas y estanterías, encontramos un escritorio y mesa, una prensa de encuadernación y varios textos bíblicos y dibujos en las paredes alusivos al oficio del archivo. Actualmente ambas salas han sido habilitadas para archivo, en la 2." se han ordenado los protocolos e impresos y en la 1." el resto de documentos en armarios metálicos.

Según el inventario de 1732 además de los armarios que guardaban los quinqui libri y demás, habia un arca mayor, donde estaba el erario, el dinero de los censales y clero, los privilegios de 
donde ha permanecido hasta ahora, salvo un corto período en que se instaló en la sacristía (51).

Comprende varias secciones, la mayoría de ellas desde la segunda mitad del siglo XVI, coincidiendo con los decretos dados para los libros parroquiales en el Concilio de Trento (1545-1563) (52), si bien debió contener documentación anterior, conservándose un libro de bautismos que inicia en 1529 (53). El archivo constaba, según se desprende de los distintos informes de las Visitas Pastorales y de varios inventarios (54), además de los documentos que se conservan de varios libros de fábrica, desde el siglo XVI, de 7 libros más de noticias sueltas, de los llamados "privilegios antiguos", libros de visitas de amortización, libros de coro... etc.; siendo de destacar el hecho de que la desaparición de esta documentación data del período comprendido entre 1962 (fecha del último inventario) y el momento actual.

El abundante número de plazas y la gran cantidad de trabajo por el

amortización, varias concordias, cuentas, bulas y otros papeles; el arca menor, dejada por el Dr. Gabriel Hernández con los libros de su administración, autos de censales, testamento y fundación del beneficio que dejó en Denia y el arca cajón con las cuentas de los colectores y cobradores del año 1693 en adelante, otros papeles de deudas del clero y de la renta de la iglesia, su aplicación y lo que debe la fábrica. En 1918 habian 8 libros de música, una estantería con cláusulas testamentarias y documentos antiguos, un armario con los libros sacramentales, otro con los expedientes matrimoniales, documentos importantes y los boletines del obispado, dos sillones viejos, 4 sillas, una mesa escritorio con servicio de escribir, un quinqué y un par de tijeras.

(51) En 1978 fueron bajados los libros a la sacristía y puestos en unos armarios metálicos. El traslado y la colocación, sin previa ordenación, contribuyó a eliminar la primitiva organización y a poner en peligro ésta, debido a la humedad de la sala. Tarea nuestra fue su ordenación, inventario y traslado a su ubicación primitiva, lugar de condiciones óptimas para su conservación.

(52) "En diversos capítulos de las sesiones 7,21, 24 y 25 los padres conciliares legislan sobre materias conexas con la vida parroquial, tales como las fábricas de las iglesias, las fundaciones piadosas, la observancia en el cumplimiento de las mandas y legados' espirituales de los feligreses, la erección canónica de cofradias y hermandades devocionales, pero sobre todo... el minucioso control y registro de la administración de sacramentos... Con esto no se quiere decir que antes de Trento las iglesias no llevasen a su modo libros de gestión, prueba de ello es la abundancia de parroquias que conservan documentación anterior." (Cfr. REPRESA RODRIGUEZ, A., op. cit., págs. 94-95.) Posteriormente el código de Derecho Canónico recogerá varias disposiciones referentes a los libros del archivo en los cánones 383, 384, 470, 2.383 y 2.406... señalando la obligación de hacer un inventario del mismo, las normas para su utilización, los libros que lo deben componer..., normas que se llevaban a cargo según se desprende de un inventario de la parroquia de 1923 (A.P.A. Inventarios, 5).

(53) Testimonios de la existencia de documentos anteriores son además del libro de Bautismos de 1529 que se conserva, varias bulas que encuadernan protocolos, un documento suelto del siglo XV, y la mención en los libros de Visitas e inventario de 1732 de libros anteriores.

(54) Véase la sección VII: Inventarios de Archivos. 
creciente aumento de legados, fundaciones, censos... hizo que desde un primer momento la parroquial de Ayora contase con uno o dos archiveros que se encargaban de su archivo. Podriamos a través de los libros racionales dar el nombre de todos los que asumieron este cargo desde el siglo XVI, pero carece de excesivo interés, por lo que sólo constataremos los nombres de Eufrosino Martínez Azorín, en el primer tercio del siglo XIX, que tras hacerse cargo del archivo varios años escribió varias obras sobre la historia de Ayora y su valle; y de D. Vicente Pastor Egea, autor del inventario del archivo de 1962, quien realizó una buena ordenación del mismo sobre la cual hemos desarrollado la nuestra, a pesar de haberse deshecho en parte con el último traslado de los fondos a la sacristía.

Los estatutos de la parroquia de 1595 (55) citan entre las obligaciones del archivero, que debía reunir unos requisitos mínimos (56), las de:

1. Tener a su cargo la custodia de los libros del archivo y poseer una de las dos llaves del mismo (57).

2. Llevar los libros de rentas, cabrevar los censales, guardar los libros de censales viejos, de cláusulas testamentales, de entradas y salidas, doblas, títulos de misas, aniversarios, cantidades y a quien se recibían... Estos libros eran llevados con la ayuda del racional, síndico, colectores, contadores-clavarios, vicario y demás presbíteros (58).

3. Hacer un inventario de todo el archivo.

4. Meter las cantidades en el arca de las tres llaves.

5. Tener abierto el archivo en las horas acostumbradas para el uso de los libros por el clero y otros que los requieran.

(55) A.P.A. Visitas, I, fol. 75 r y ss.

(56) "Otro si ordenamos que los archiveros sean de los más inteligentes y papelistas, que se dé a cada uno 2 libras de salario y que cada semana tengan 2 dias de presencia, los cuales empleen en mirar y reconocer los censos, autos y demás papeles del archivo, y que los vaya calendariando cada uno en su lugar, llevando con claridad cada administración de por sí. Y que éstos tengan obligación - pues tendrán más clara noticia de las rentas de la iglesia- de hacer los cuadernos del colector, y los de celebración - y el racional-con la obligación y renta, para que la cumpla y distribuya sin agravio de nadie" (A.P.A. Visitas, II, fol. 250 v.).

(57) "Se pongan todos juntos en el archivo los libros de cuentas y los de visitas y para que estén más custodiados se pongan en un arca o armario que tenga dos llaves, la una de ellas tenga el vicario foráneo y la otra el archivero, el cual archivero siempre que el vicario le pidiese ver algún libro tenga obligación de acudir con la llave» (A.P.A. Visitas, II, fol. 206 r).

(58) Para ello contará con la colaboración del resto de presbíteros de forma que "cualquier clérigo responda a las preguntas del archivero" (A.P.A. Visitas, lil, fol. $189 \mathrm{r}$ ) y ulos poseedores de capellanías entreguen los títulos al archivero" (A.P.A. Visitas, III, fol. $336 \mathrm{r}$ ). 
6. Tener ordenados los libros para que cuando se pidan puedan mostrarlos y encargarse de su buena conservación.

7. Entregar los libros que se pidan.

8. Expedir o mandar expedir las copias, certificaciones o licencias requeridas.

9. Exigir el permiso debido para sacar libros y anotar quién lo saca y para qué (59).

10. No olvidar sus obligaciones elementales de cara a la celebración del culto y su ministerio sacerdotal.

Reunidas las distintas secciones de acuerdo con su diferente finalidad que las hizo nacer, podemos hablar de varios grupos:

$11^{\circ}$ Registros Parroquiales: Formada por los libros sacramentales o quinque libri, la documentación complementaria (expedientes matrimoniales, licencias sepultura, declaraciones de bautismo...) y libros de Statu animarum, tiene gran valor por su continuidad para estudios demográficos y sociales.

2. Gobierno y acción pastoral: A nivel de diócesis o parroquia está formado por la correspondencia con la Curia y con otros cargos civiles, indulgencias, libros de padrones parroquiales, libros de visitas pastorales y en cierta medida por los libros de culto parroquial, racionales, cofradías o grupos... en la medida en que también nos informan sobre dicha acción.

Dentro de este apartado conviene que analicemos las Visitas Pastorales, dada la abundancia de datos que proporciona y la riqueza de los mismos, características que saltan a la vista al analizar los distintos pasos de cada Visita:

A) Edicto y comienzo: El obispo o el visitador era recibido por el cabildo parroquial, por las autoridades locales y el pueblo a la entrada de la iglesia, procediéndose después a la lectura del edicto general de la visita, la visita del Santo Sacramento, responso y misa general solemne y administración del sacramento de la confirmación.

B) Visita e inspección de la lglesia: Inspección e inventario de cada una de las capillas y altares, de las reliquias, de la sacristía con sus alhajas y objetos de culto, pila de bautismo y óleos, libros sacramentales y otros libros del archivo.

(59) “Todos los libros se pongan en el archivo, menos los corrientes y que se entere de ello el archivero, haciendo inventario de todos los libros y si alguna vez se quisiese sacar un libro de los referidos del archivo, no lo entregue el archivero sin que primero haga confesión por escrito de lo que lleva, para que encargo... a fin de que sepa el archivero en poder de quien... y se pueda recobrar prontamente" (A.P.A. Visitas III, fol. $46 \mathrm{v} . .^{\circ}$ ). 
C) Visita de la marcha del culto y administración: A la vista de los respectivos libros se hacía un informe desde el año de la última visita de las misas perpetuas, cargo y descargo de misas votivas, anuales, testamentarias y capellanías; de doblas, medias festividades, festividades enteras, aniversarios, amortizaciones y otras misas; sepulturas, platos, fábrica mayor y menor, cuentas de colectores y alcances y memoria de la renta del clero en censos y censales.

D) Visita de instituciones anexas: Inspección de ermitas y cofradías con inventarios y cuentas de las mismas.

E) Final y publicación de la Visita: A los mandatos y ordinaciones, que alguna vez se convierten en estatutos para el mejor gobierno de la iglesia, seguía finalmente la publicación de la Visita.

3. ${ }^{\circ}$ Instituciones parroquiales: Libros de Cofradías, capellanías y otras obras Pías (60), hospital, cementerio y ermitas.

4. Administración de bienes y rentas: Cabreves de censos y censales, inventarios, libros y cuadernos de censos y rentas (61), cuentas de los colectores, fábrica parroquial y en cierto modo los racionales (62) y libros de culto (63), así como otros libros de administración ya incluidos en otros apartados.

5. Documentación Notarial: Abarca además de los documentos judiciales y procesos, los testamentos, los protocolos notariales y las

(60) Sobre esta sección véase BARREIRO MALLON, B., E/ sentido religioso del hombre ante la muerte en el antiguo régimen. Un estudio sobre archivos parroquiales y testamentos notariales, en "Actas de las I Jornadas de metodología aplicada a las ciencias históricas. $V$. Paleografia y archivística" (Santiago de Compostela, 1976), págs. 181-197; PLA ALBEROLA, P. J., Los beneficios eclesiásticos y sus rentas a través de las Visitas Pastorales: La parroquia de Santa María de Cocentaina a principios de/siglo XVIII. "Anales Valentinos" VII (1981), págs. 255 y ss.; Código de Derecho Canónico y legislación Complementaria, (Madrid, 1962), cánones 1409 a 1551.

(61) Responden a varios títulos: "Cuadernos de los censos que responden particulares al reverendo clero de Ayora", "Cuaderno de los censos y rentas amortizadas de la parroquial de Ayora, siendo su colector...", "Memoria de toda la renta amortizada", "libro de la renta de esta iglesia". Los libros de censos presentan formato $16 \times 22 \mathrm{~cm}$.

(62) Referentes a la administración de la iglesia, corresponden a actos y actividades del culto, llevando un control de todos los quehaceres religiosos de un año. Comienzan en 21 de diciembre con la elección de cargos y a continuación un registro del culto parroquial realizado y de la renta percibida (véase Estatutos del Racional en A.P.A. Visitas I, fols. 73-74).

(63) Bien las manos o memorias de misas, libros de misa o minutarios de culto y los anuales de misas, aniversarios, festividades y capellanías.

Las manos de misas en folios de distintos tamaños, generaimente de doble folio cosidos o en carpetas aparecen con las hojas divididas en recuadros, donde se anotan las distintas misas de cada día, el presbítero que las ha de oficiary otras anotaciones breves respecto al carácter de la misa.

Los libros de misas o minutarios de culto, en formato $10 \times 30 \mathrm{~cm}$., anota las misas dichas por cada cura, fecha, hora, cantidad e intención: “Por el Dr. Gabriel Hernández y suyos -4 s. 2 d. - 1 julio-12-Dr. Teruel". 
cláusulas testamentales, que aunque su función es respaldar las rentas legadas a la parroquia y las obligaciones sobre ellas, suponen un registro notarial al trasladar las cláusulas de los testamentos de particulares ante notario (64).

En 1732 el inventario del archivo parroquial sólo habla de 2 protocolos de Juan Bautista Ortín y 6 de Juan Martínez. En la actualidad hay 308 volúmenes y 20 cajas entre protocolos, minutarios o rebedores e índices ordenados alfabéticamente y por años. Estos protocolos unidos a los conservados en el A.R.V. (65) y a un índice del notario Pedro Gómez (1737-38) en el Archivo Municipal constituyen los fondos notariales de Ayora, que según Martínez Azorín gozaba de una buena notaría con documentación desde el siglo XV (66). A principios de siglo desapareció la notaría, lo cual unido a la simbiosis frecuente notario público-notario eclesiástico explicara la razón de este fondo. Los notarios, además de en su calidad de notarios públicos de Ayora, los veremos actuar como escribanos del señor y su procurador general, del justicia, de la sala del consejo, del cabildo parroquial (67) e incluso aparecerán en los mandatos y publicación de las Visitas pastorales.

De esta forma el archivo, bajo la dirección del archivero y la inspección periódica del vicario y visitas, va a cumplir la obligación de "llevar, anotar, conservar y custodiar cuantos libros fueran necesarios para constancia y testimonio del ejercicio de los ministerios parroquiales» (68), tanto en el ámbito pastoral (culto y administración de sacramentos), en el económico (administración de bienes y rentas), como en el jurídico-social. A dichas tareas hacen referencia los textos bíblicos que adornan las paredes del archivo (69).

Los libros anuales de misas, aniversarios, festividades y capellanías, comparables al racional, recogen con letra muy cuidada el calendario santoral acompañado de los beneficios, aniversarios, anuales... de cada dia y demás observaciones.

(54) "In hoc libro continetur clausulas operarum piarum simple ex testamentis..." "Libro de últimas voluntades y obras pías $*$. Consignan el día, el fallecido, la cláusula o cláusulas, notario y fecha del testamento.

(65) 221 volúmenes de 21 notarios, de cuatro de los cuales (Miguel Antonio del Campo, Esteban del Campo, Lorenzo Marti y Juan Francisco Rico) hay también protocolos en el archivo parroquial.

(66) "Este valle goza de una buena notarfa... Tiene un archivo que se remonta al s. XV, el cual consta de cerca de 550 volúmenes o protocolos, los cuales se conservan en muy buen estado* (Cfr. MARTINEZ AZORIN, E., Historia de la..., pág. 81).

(67) «lacobus Yvañez, escriba vicariatus Ayore», «Alfonsus Blasius de Pina, escriba vicariatus Ayore" (A.P.A. Visitas I, 1607 y 1614).

(68) Cfr. REPRESA RODRIGUEZ, A., op. cit., págs. 94-95.

(69) "Signa librum usque ad tempus statum" (Dan. 12-4), "Sacribantur haec in generatione altera, et populus qui creabitur, laudabit Dominum» (Salm. 101 (102)-19), "Benefacitis scribentes nobis" (I Mach. 12-22). 


\begin{tabular}{|c|c|c|c|c|c|c|c|c|c|c|c|c|}
\hline \multirow{2}{*}{ 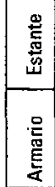 } & \multirow{2}{*}{$\frac{Y}{\square}$} & \multirow{2}{*}{ N } & \multirow{2}{*}{$\frac{\stackrel{m}{\sim}}{\square}$} & \multirow[t]{2}{*}{$m$} & \multirow{2}{*}{$\begin{array}{l}\text { 峁 } \\
\text { 号 } \\
\mathscr{\Omega}\end{array}$} & \multirow{2}{*}{\multicolumn{3}{|c|}{$\frac{\infty}{\sum_{\frac{\alpha}{\alpha}}^{\frac{\alpha}{\alpha}}}$}} & & & \multirow{2}{*}{$\frac{+}{0}$} & \multirow{2}{*}{ 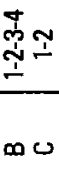 } \\
\hline & & & & & & & & & & & & \\
\hline$\frac{\pi}{50}$ & - & - & - & - & - & - & - & - & - & - & - & - \\
\hline ż & & & & & $m$ & - & - & $\mathscr{q}$ & - & - & & $\theta$ \\
\hline 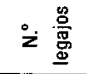 & & & & & & $\sigma$ & & 8 & & + & & \\
\hline 亡 & $y$ & ம & $\bar{N}$ & $\mathscr{\sim}$ & $\Xi$ & & L & & $\infty$ & & + & 怘 \\
\hline 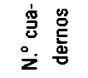 & & & & & & & & & & & $v$ & \\
\hline 号 & 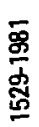 & $\frac{\infty}{\frac{\infty}{\sigma}} \frac{1}{\frac{1}{n}}$ & 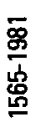 & $\frac{\Phi}{\frac{\$}{\phi}}$ & $\begin{array}{l}\frac{\infty}{\sigma} \\
\frac{\sigma}{\phi} \\
\stackrel{\infty}{\infty}\end{array}$ & 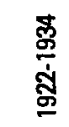 & $\begin{array}{l}\grave{\$} \\
\not{\phi} \\
\stackrel{\infty}{\infty}\end{array}$ & $\begin{array}{l}\overline{\$} \\
\text { \% } \\
\text { d్ } \\
\Phi\end{array}$ & 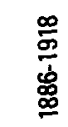 & $\frac{\frac{\text { p }}{\sigma}}{\frac{\phi}{\sigma}}$ & 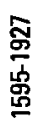 & 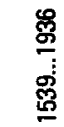 \\
\hline $\begin{array}{l}\text { zo } \\
\text { 总 } \\
\text { 出 }\end{array}$ & 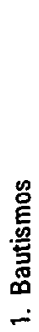 & 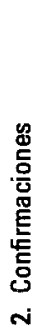 & 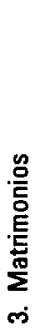 & 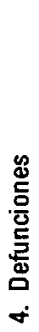 & 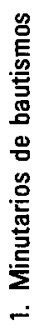 & 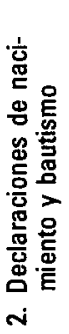 & 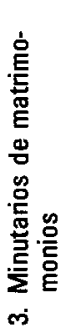 & 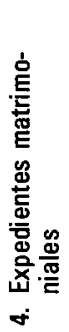 & 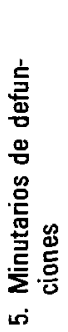 & 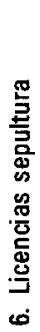 & & \\
\hline 崖 & 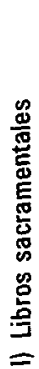 & & & & 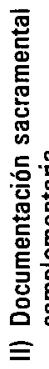 & & & & & & 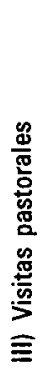 & 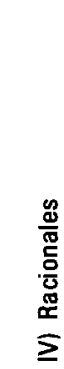 \\
\hline
\end{tabular}




\begin{tabular}{|c|c|c|c|c|c|c|c|c|c|c|c|c|}
\hline$\phi$ & $\nabla$ & $\theta$ & $N$ & $m$ & + & $N$ & $N$ & $N$ & $N$ & $\nabla$ & $\sigma$ & 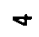 \\
\hline س & س & ш & ט & ט & ט & 山 & س & س & س & $<$ & $<$ & w \\
\hline- & - & - & $\sigma$ & - & - & - & - & - & - & - & - & - \\
\hline & - & - & un & In & & $m$ & - & - & - & & & - \\
\hline$=$ & $N$ & & $\mathscr{B}$ & $\mathscr{8}$ & $\infty$ & $r$ & (1) & & & $\forall$ & $=$ & \\
\hline- & 모 & m & & & & $\mathscr{\infty}$ & $m$ & 品 & $\mathscr{q}$ & $m$ & & or \\
\hline$\frac{9}{\frac{8}{5}}$ & $\frac{\stackrel{9}{5}}{\frac{5}{5}}$ & 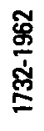 & 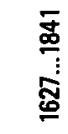 & 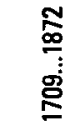 & 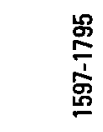 & 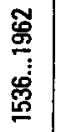 & $\begin{array}{l}\frac{\Phi}{\Phi} \\
\frac{\infty}{\vdots} \\
\frac{\infty}{\infty}\end{array}$ & 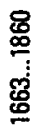 & 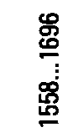 & 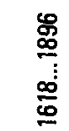 & 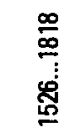 & $\frac{\infty}{\infty}$ \\
\hline & : & $\begin{array}{l}\vdots \\
\vdots \\
\vdots \\
\vdots \\
\vdots \\
\vdots \\
\vdots\end{array}$ & 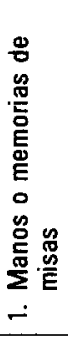 & 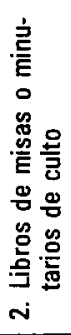 & 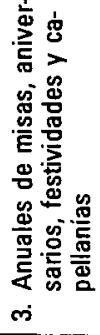 & 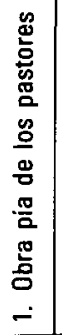 & 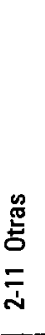 & $\begin{array}{l}\vdots \\
\vdots \\
\vdots \\
\vdots \\
\vdots \\
\vdots \\
\vdots\end{array}$ & $\begin{array}{l}\vdots \\
\vdots \\
\vdots \\
\vdots \\
\vdots \\
\vdots \\
\vdots\end{array}$ & $\begin{array}{l}\vdots \\
\vdots \\
\vdots \\
\vdots \\
\vdots \\
\vdots\end{array}$ & 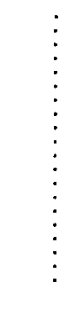 & $\begin{array}{l}\vdots \\
\vdots \\
\vdots \\
\vdots\end{array}$ \\
\hline 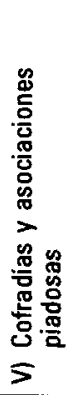 & 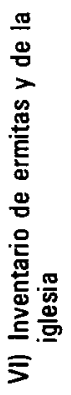 & 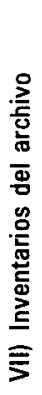 & 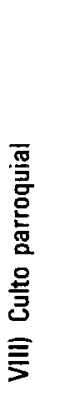 & . & & 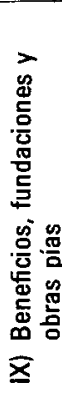 & & 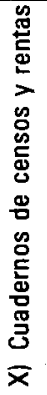 & 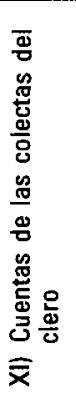 & 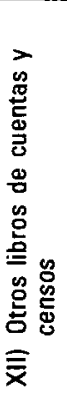 & 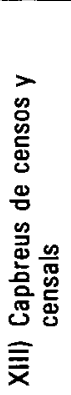 & 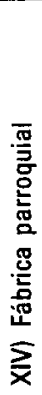 \\
\hline
\end{tabular}




\begin{tabular}{|c|c|c|c|c|c|c|c|c|c|c|c|c|c|}
\hline$m$ & m & $m$ & $m$ & $\nabla$ & $\nabla$ & - & - & $\stackrel{\sim}{\sim}$ & \multirow{2}{*}{ 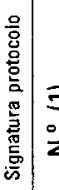 } & \multirow{2}{*}{$\begin{array}{l}E \\
z\end{array}$} & \multirow{2}{*}{ ָ } & \multirow{2}{*}{ ल} & \multirow{2}{*}{$\Phi$} \\
\hline w & $\omega$ & $w$ & س & س & س & س & 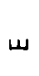 & $\varangle$ & & & & & \\
\hline- & - & - & - & - & - & - & - & - & & $N$ & $N$ & $N$ & $N$ \\
\hline- & $v$ & - & $m$ & - & - & & - & \pm & & & - & & 1 \\
\hline & & & $\sim$ & & & & & $\mathscr{N}$ & & & & & \\
\hline- & $m$ & $m$ & & & & \pm & & & & 尺ి & - & $\infty$ & - \\
\hline N & $\infty$ & ما & & & & & $\stackrel{\infty}{ }$ & है & & & & & \\
\hline 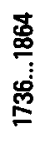 & 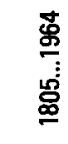 & 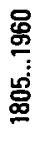 & 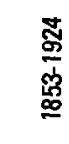 & $\frac{\sqrt{n}}{\frac{\dot{d}}{\mathscr{8}}}$ & 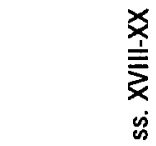 & 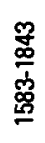 & $\frac{ \pm}{5}$ & 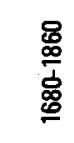 & & 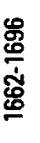 & $\stackrel{8}{\mathbb{8}}$ & $\frac{\mathfrak{N}}{\frac{\mathfrak{d}}{E}}$ & 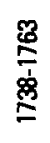 \\
\hline 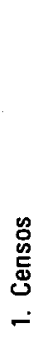 & 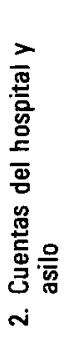 & $\frac{\infty}{\frac{9}{2}}$ & $\vdots$ & $\begin{array}{l}\vdots \\
\vdots \\
\vdots \\
\vdots\end{array}$ & $\begin{array}{l}\vdots \\
\vdots \\
\vdots\end{array}$ & $\begin{array}{l}\vdots \\
\vdots \\
\vdots \\
\vdots \\
\vdots \\
\vdots \\
\vdots\end{array}$ & $\begin{array}{l}\vdots \\
\vdots \\
\vdots \\
\vdots \\
\vdots\end{array}$ & $\begin{array}{l}\vdots \\
\vdots \\
\vdots \\
\vdots\end{array}$ & & 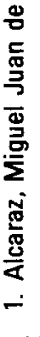 & 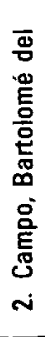 & 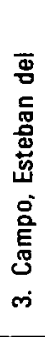 & 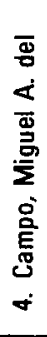 \\
\hline 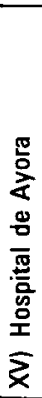 & ' & & 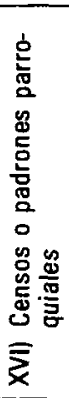 & 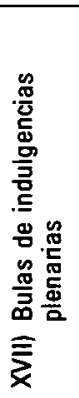 & 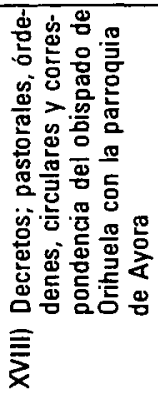 & 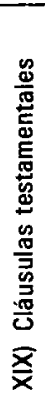 & 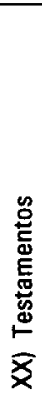 & 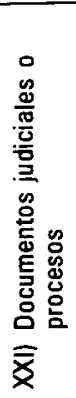 & 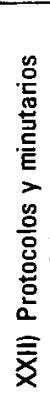 & & & & \\
\hline
\end{tabular}




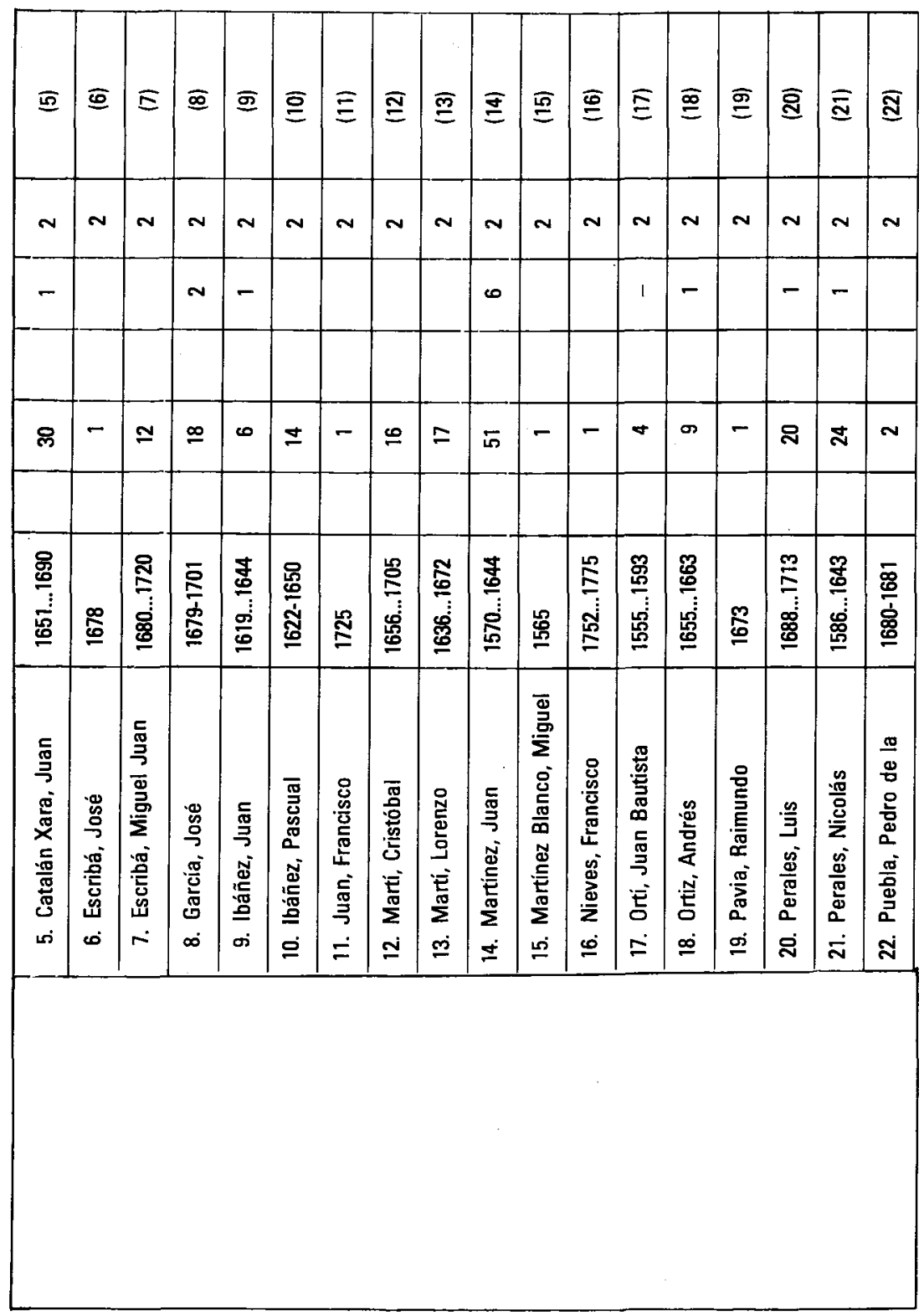




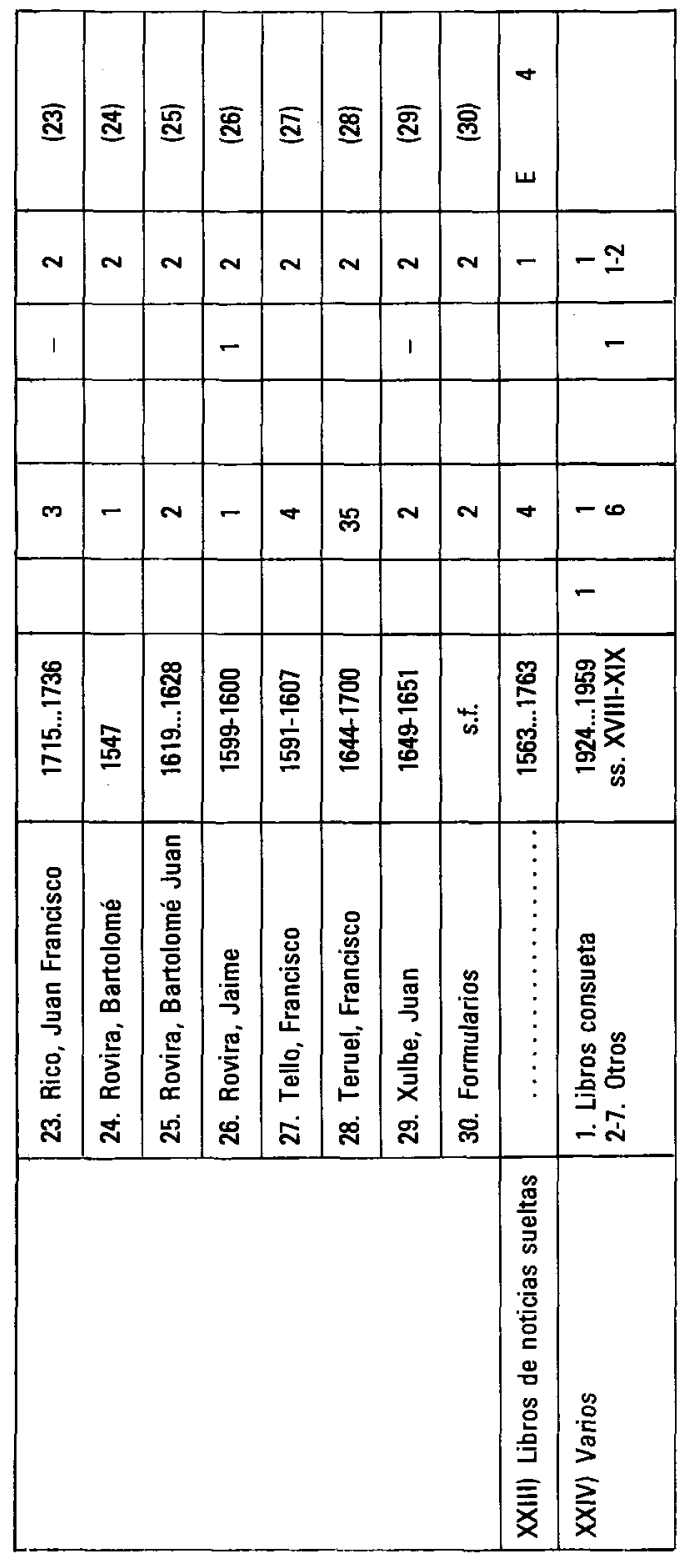


I) LIBROS SACRAMENTALES (70).

1. BAUTISMOS:

1.1. 1529-1730. Indice de Bautismos. 309 fol. in fol,, foliado, sin cubiertas.

1.2. 1529-1545. Libro de Bautismos. 122 fol. in $15 \times 35 \mathrm{cms}$., foliado. Cubiertas en pergamino.

1.3. 1550-1562. Libro de Bautismos. 149 fol. in $1 / 2$ fol., foliado. Cubiertas pergamino.

1.4. 1550-1579. Libro misceláneo de Bautismos y confirmaciones. 192 fol. in fol., foliado. Cubiertas pergamino.

1.5. 1580-1619. Libro de Bautismos. 463 fol. in fol., foliado. Cubiertas pergamino. En una antigua organización aparece como $4 .^{\circ}$ libro de Bautismos del archivo.

1.6. 1657-1684. Libro de Bautismos. 323 fol. in fol., foliado. Cubiertas pergamino.

1.7. 1685-1731. Libro de Bautismos. 434 fol. in doble fol., foliados. Cubiertas en pergamino. En la antigua organización era el $7 .^{\circ}$ libro de bautismos.

1.8. 1732-1839. Indice de Bautismos. 308 fol. in fol., sin foliar y sin cubiertas.

1.9. 1732-1756. Libro de Bautismos. 440 fol. in doble fol., foliados. Cubiertas en pergamino.

1.10. 1757-1769. Libro de Bautismos. 290 fol. in doble fol., foliados. Cubiertas en pergamino y cierre con correa.

1.11. 1769-1779. Libro de Bautismos. 286 fol. in doble fol. foliado. Cubiertas en pergamino con cierre de correa roto.

1.12. 1780-1790. Libro de Bautismos. 288 fol. in doble fol., foliados. Cubiertas en pergamino.

1.13. 1791-1802. Libro de Bautismos. 295 fol. in doble fol., foliado. Cubiertas en pergamino. Número 12 de la antigua organización.

1.14. 1800-1839. Indice de Bautismos. 115 fol. in doble fol., sin foliar. Cubierta de Cartone. Hasta 1839 hace mención de 16 libros bautismales.

1.15. 1802-1815. Libro de Bautismos. 446 fol. in fol., foliado. $\mathrm{Cu}-$ biertas pergamino.

(70) Los libros sacramentales del siglo XX permanecen en las oficinas de la casa Abadía junto con otros documentos y no en el archivo debido a su vigencia en la actualidad. 
1.16. 1815-1831. Libro de Bautismos. 189 fol. in fol., foliado. Cubiertas pergamino.

1.17. 1832-1839. Libro de Bautismos. 190 fol. in doble fol., foliado. Cubiertas en pergamino.

1.18. 1840-1884. Indice de Bautismos. 126 fol. in fol., foliado. $3 \mathrm{~h}$. en blanco. Cubierta cartone.

1.19. 1840-1889. Indice de Bautismos. 145 fol. in doble fol., foliado. Cubiertas cartone.

1.20. 1845-1854. Libro de Bautismos. 194 fol. in fol., foliado. $\mathrm{Cu}-$ biertas pergamino.

1.21. 1850-1851. Libro de Bautismos. 38 fol. in doble fol., foliado. Cubiertas pergamino.

1.22. 1851-1855. Libro de Bautismos. 244 fol. in fol., foliado. $\mathrm{Cu}$ biertas cartone.

1.23. 1856-1858. Libro de Bautismos. 173 fol. in fol., foliado. Cubiertas cartone.

1.24. 1858-1866. Libro de Bautismos. 500 fol. in fol., foliado. Cubiertas pergamino. Número 21 en la antigua organización.

1.25. 1866-1869. Libro de Bautismos. 198 fol. in fol., foliado. Cubiertas cartone sin portada de delante.

1.26. 1869-1872. Indice y libro de Bautismos. 199 fol. in fol., foliado $+3 \mathrm{~h}$. sin foliar del indice. Cubierta cartone.

1.27. 1872-1878. Libro de Bautismos. 300 fol. in fol., foliado.

1.28. 1878-1884. Libro de Bautismos. 299 fol. in fol., foliado. Libro 25 antigua organización.

1.29. 1884-1889. Libro de Bautismos. 289 fol. in fol., foliado.

1.30. 1890-1931. Indice de Bautismos.

1.31. 1890-1891. Libro de Bautismos. 113 fol. in fol., foliado.

1.32. 1892-1895. Libro de Bautismos. 233 fol. in fol., foliado.

1.33. 1893-1903. Libro de Bautismos. 407 fol. in fol., foliado.

1.34. 1903-1907. Libro de Bautismos. 239 fol. in fol., foliado.

1.35. 1907-1912. Libro de Bautismos. 246 fol. in fol., foliado.

1.36. 1912-1917. Libro de Bautismos. 299 fol. in fol., foliado.

1.37. 1917-1922. Libro de Bautismos. 248 fol. in fol., foliado.

1.38. 1922-1928. Libro de Bautismos. 304 fol. in fol., foliado.

1.39. 1928-1936. Libro de Bautismos. 303 fol. in fol., foliado.

1.40. 1932-1963. Indice de Bautismos.

1.41. 1936-1945. Libro de Bautismos. 300 fol. in fol., foliado.

1.42. 1945-1954. Libro de Bautismos. 313 fol. in fol., foliado.

1.43. 1954-1963. Libro de Bautismos.

1.44. 1964-... Libro de Bautismos. 
2. CONFIRMACIONES:

2.1. 1572-1641. Libro misceláneo de Bautismos y Confirmaciones. 187 fol. in fol., foliado. Cubiertas pergamino.

2.2. 1641-1766. Libro de confirmaciones. 281 fol. in fol., foliado. Cubiertas pergamino con pasador de broche.

2.3. 1766-1849. Libro de confirmaciones. 250 fol. in fol., foliado. Cubiertas pergamino.

2.4. 1860-1871. Libro de confirmaciones. 60 fol. in fol., foliado. Cubiertas cartone.

2.5. 1872-1927. Libro de confirmaciones.

2.6. 1946-1978. Libro de confirmaciones.

3. MATRIMONIOS:

3.1. 1565-1884. Indice de matrimonios. 196 fol. in fol. Sin foliar. Cubiertas pergamino.

3.2. 1565-1607. Libro misceláneo de matrimonios y defunciones de niños (alvats). 190 fol. in fol., foliado. Cubiertas pergamino. Número 1 en la antigua organización de los libros matrimoniales del archivo.

3.3. 1566-1879. Indice de matrimonios. 154 fol. in doble fol., sin foliar. Cubiertas cartone. Habla de 10 libros de matrimonios hasta 1879.

3.4. 1608-1650. Libro de matrimonios. 242 fol. in fol., foliado. Cubiertas pergamino.

3.5. 1651-1746. Libro de Matrimonios. 504 fol. in fol., foliado. Sin cubiertas.

3.6. 1747-1775. Libro de matrimonios. 289 fol. in fol., foliado. Cubiertas pergamino. Falta la cubierta de detrás. Número 4 de la antigua organización.

3.7. 1775-1798. Libro de matrimonios. 304 fol. in fol., foliado. Cubiertas pergamino.

3.8. 1799-1826. Libro de matrimonios. $184 \mathrm{fol}$. in fol., foliado. Cubiertas pergamino.

3.9. 1826-1851. Libro de matrimonios. 156 fol. in fol., doble, foliado. Cubiertas pergamino.

3.10. 1851-1858. Libro de matrimonios. 94 fol. in fol., foliado. Cubiertas cartone.

3.11. 1858-1877. Libro de matrimonios. 301 fol. in fol., foliado.

3.12. 1878-1889. Libro de matrimonios. 395 fol. in fol., foliado. Algo deteriorado, le faltan las primeras páginas.

3.13. 1890-1940. Indice de matrimonios.

3.14. 1890-1891. Libro de matrimonios. 56 fol. in fol., foliado. 
3.15. 1892-1905. Libro de matrimonios. 149 fol. in fol., foliado.

3.16. 1905-1920. Libro de matrimonios. 182 fol. in fol., foliado.

3.17. 1920-1932. Libro de matrimonios. 149 fol. in fol., foliado.

3.18. 1932-1950. Libro de matrimonios. 201 fol. in fol., foliado.

3.19. 1941-1969. Indice de matrimonios.

3.20. 1950-1978. Libro de matrimonios.

3.21. 1978-... Libro de matrimonios.

4. DEFUNCIONES:

4.1. 1608-1615. Libro misceláneo de matrimonios y defunciones de niños (Alvats). 17 fol. in fol., sin foliar. Cubiertas pergamino.

4.2. 1779-1889. Indice de defunciones. 150 fol. in doble fol., sin foliar. Cubiertas cartone. Habla de 11 libros de defunciones hasta 1889.

4.3. 1779-1794. Libro de defunciones. 314 fol. in fol. foliado. Mal estado (Hongos). Cubiertas pergamino.

4.4. 1795-1818. Libro de defunciones. 443 fol. in fol., foliado. Cubiertas pergamino. Número 2 en la antigua organización.

4.5. 1818-1831. Libro de defunciones. 100 fol. in doble fol., foliado. Cubiertas pergamino.

4.6. 1832-1839. Libro de defunciones. 134 fol. in fol., foliado. Cubiertas pergamino.

4.7. 1839-1851. Libro de defunciones. 149 fol. in fol., foliado. Cubiertas pergamino.

4.8. 1852-1885. Indice de defunciones. 160 fol. in fol., sin foliar y sin cubiertas.

4.9. 1851-1855. Libro de defunciones. 203 fol. in fol., foliado. Cubiertas Cartone.

4.10. 1856-1858. Libro de defunciones. 22 fol. in fol., foliado. $\mathrm{Cu}-$ biertas cartone.

4.11. 1858-1865. Libro de defunciones. 200 fol. in fol., foliado. Cubiertas pergamino.

4.12. 1865-1871. Libro de defunciones. 159 fol. in fol., foliado. Cubiertas de cartón muy deterioradas.

4.13. 1871-1882. Libro de defunciones. 296 fol. in fol., foliado. Cubiertas cartone.

4.14. 1882-1889. Libro de defunciones. 298 fol. in fol., foliado. Sin cubiertas.

4.15. 1890-1963. Indice de defunciones.

4.16. 1890-1891. Libro de defunciones. 70 fol. in fol., foliado. 16 últimos folios en blanco. 
4.17. 1892. Libro de defunciones. 13 fol. in fol., foliado. Cubiertas pergamino. 299 hojas sin llenar.

4.18. 1892-1899. Libro de defunciones. 285 fol. in fol., foliado. Cubiertas cartone.

4.19. 1899-1903. Libro de defunciones. 157 fol. in fol., foliado.

4.20. 1903-1909. Libro de defunciones. 200 fol. in fol., foliado.

4.21. 1909-1917. Libro de defunciones. 208 fol. in fol., foliado.

4.22. 1917-1924. Libro de defunciones. 249 fol. in fol., foliado.

4.23. 1924-1944. Libro de defunciones. 249 fol. in fol., foliado.

4.24. 1944-1968. Libro de defunciones.

4.25. 1963-1970. Indice de defunciones.

4.26. 1969-... Libro de defunciones.

5. Libro de defunciones de la parroquia de Santa Maria de Elche (1662-1663). 70 fol. in 1/4, sin foliar. Cubiertas de pergamino. Debió traerlo algún sacerdote que después de ser presbítero en Elche, lo fue de Ayora (¿mossen Martí Pastor?).

II) DOCUMENTACION SACRAMENTAL COMPLEMENTARIA

1. MINUTARIOS DE BAUTISMOS (LIBROS):
1.1. $1886-1887$
1.5. $1897-1900$
1.9. $1910-1914$
1.2. $1889-1892$
1.6. $1900-1907$
1.10. $1014-1915$
1.3. $1892-1894$
1.7. $1904-1908$
1.11. $1915-1918$
1.4. $1894-1899$
1.8. $1908-1910$

2. DECLARACIONES DE NACIMIENTO Y BAUTISMO (LEGAJOS):
2.1. 1922
2.4. 1925
2.7. 1929
2.2. 1923
2.5. 1926-1927
2.8. 1930
2.3. 1924
2.6. 1928
2.9. $1933-1934$

3. MINUTARIOS DE MATRIMONIOS (LIBROS):
3.1. 1889-1909
3.3. 1901-1910
3.5. $1957-1967$
3.2. $1892-1901$
3.4. 1928-1936

4. EXPEDIENTES MATRIMONIALES (LEGAJOS):
4.1. $1826,38,42$ a 48
4.6. $1865-69$
4.11. $1880-83$
4.2. $1850-54$
4.7. $1870-72$
4.12. $1884-86$
4.3. $1855-57$
4.8. $1872-74$
4.13. $1887-89$
4.4. $1858-1860$
4.9. $1875-76$
4.14. $1890-93$
4.5. $1861-64$
4.10. $1877-79$
4.15. 1895 


$\begin{array}{lll}\text { 4.16. } 1896 & 4.31 .1927 & 4.46 .1957-58 \\ \text { 4.17. } 1897 & 4.32 .1930 & 4.47 .1959-60 \\ \text { 4.18. } 1898 & 4.33 .1931 & 4.48 .1961-62 \\ \text { 4.19. } 1900-2 & 4.34 .1932 & 4.49 .1963 \\ \text { 4.20. } 1903-5 & 4.35 .1933-1935 & 4.50 .1964 \\ \text { 4.21. } 1906-9 & 4.36 .1936 & 4.51 .1965 \\ \text { 4.22. } 1910 & 4.37 .1939-40 & 4.52 .1966 \\ \text { 4.23. } 1915 & 4.38 .1941-42 & 4.53 .1967 \\ \text { 4.24. } 1916 & 4.39 .1943-44 & 4.54 .1968-69 \\ 4.25 .1917 & 4.40 .1945-46 & 4.55 .1970-71 \\ 4.26 .1918 & 4.41 .1947-48 & 4.56 .1972-73 \\ 4.27 .1919 & 4.42 .1949-50 & 4.57 .1974-75 \\ 4.28 .1921 & 4.43 .1951-52 & 4.58 .1976-77 \\ 4.29 .1922 & 4.44 .1953-54 & 4.59 .1978-79 \\ 4.30 .1926 & 4.45 .1955-56 & 4.60 .1980-81\end{array}$

5. MINUTARIOS DE DEFUNCIONES (LIBROS):
5.1. 1886-1889
5.3. $1895-1900$
5.5. $1909-1911$
5.2. $1892-1894$
5.4. $1900-1909$
5.6. $1911-1918$

6. LICENCIAS SEPULTURA (LEGAJOS):
6.1. $1919-1920$
6.3. $1925-1926$
6.4. 1930
6.2. $1923-1924$

III) LIBROS DE VISITAS PASTORALES (71)

1. Libro de Visitas de 1595-1628. 352 fol. in fol., foliado. Cubiertas pergamino.

Visitas realizadas y visitador

1.1. 1595- julio, 12 = D. José Estevan, obispo de Orihuela.

1.2. 1597, octubre, $20=D$. José Estevan, obispo de Orihuela (Fallece en Ayora durante la visita).

1.3. 1602 , octubre, 27 = Jerónimo Ruiz, vicario.

1.4. 1605 , julio, $18=$ Andrés Balaguer, obispo de Orihuela.

1.5. 1605 , octubre, $5=$ Andrés Balaguer, obispo de Orihuela.

1.6. 1610 , octubre, $20=$ Andrés Balaguer, obispo de Orihuela.

(71) Existen también dos cuadernillos con el título "Santa Visita Pastoral de la Iglesia de Ntr." Sr." de la Asunción de Ayora: 1860 y 1889" ( 8 y 9 fol. in fol. respectivamente). 
1.7. 1614, septiembre, $21=$ Andrés Balaguer, obispo de Orihuela.

1.8. 1617, septiembre, $23=$ Andrés Balaguer, obispo de Orihuela.

1.9. 1619 , octubre, $20=$ Andrés Balaguer, obispo de Orihuela.

1.10. 1621, octubre, $10=$ Andrés Balaguer, obispo de Orihuela.

1.11. 1625 , septiembre, 22 = Andrés Balaguer, obispo de Orihuela.

1.12. 1628 , octubre, $8=$ Bernardo Caballero de Paredes, obispo de Orihuela.

2. Libro de Visitas de 1637-1684. 349 fol. in fol., foliado. Cubiertas de pergamino. Falta la cubierta de delante.

2.13. 1637 , octubre, 4 = Juan García y Artes, obispo de Orihuela.

2.14. 1639 , septiembre, 18 = Juan García y Artes, obispo de Orihuela.

2.15. 1641 , septiembre, 29 = Juan García y Artes, obispo de Orihuela.

2.16. 1649 , septiembre, 11 = Juan de Orta, obispo de Orihuela.

2.17. 1652, octubre, 7 = Luis Crespi de Borja, obispo de Orihuela.

2.18. 1655, agosto, 22 = Luis Crespí de Borja, obispo de Orihuela.

2.19. 1659 , agosto 10 = Pedro Crespo, canónigo y vicario general.

2.20. 1661 , octubre, 23 = Acacio March de Velasco, obispo de Orihuela.

2.21. 1664 , septiembre, 20 = Acacio March de Velasco, obispo de Orihuela.

2.22. 1672 , julio, 14 = José Verge, obispo de Orihuela.

2.23. 1684 , julio $=$ Antonio Sánchez del Castellar, obispo de Orihuela.

3. Libro de Visitas de 1690-1732. 377 fol. in fol., foliado. Cubiertas pergamino.

3.24. 1690 , noviembre, $13=$ Antonio Sánchez del Castellar, obispo de Orihuela.

3.25. 1698 , septiembre, 28 = Antonio Sánchez del Castellar, obispo de Orihuela.

3.26. 1701, mayo, $16=$ Alejandro Pascual de Ochoa, canónigo y vicario general.

3.27. 1704 , septiembre, 28 = José de la Torre y Orumbella, obispo de Orihuela. 
3.28. 1712, noviembre, 13 = Alejandro Pascual de Ochoa, canónigo y visitador.

3.29. 1717 , octubre, 28 = Luis Pisana y Bruytón, presbítero y visitador.

3.30. 1722, septiembre, 21 = Salvador José Rodríguez de Castelblanco, obispo de Orihuela.

3.31. 1724 , febrero, 2 = Tomás Ruiz y Vilafranca, visitador general.

3.32. 1727 , septiembre, 18 = Gaspar Mazeras de Gallens, canónigo y visitador.

3.33. 1729, junio, 14 = José Flores Ossorio, obispo de Orihuela.

3.34. 1732, junio, 6 = José Flores Ossorio, obispo de Orihuela.

4. Libro de Visitas de 1734-1927, 423 fol. in fol., foliado $+8 \mathrm{~h}$. $\mathrm{Cu}-$ biertas pergamino.

4.35. 1734 , julio, $26=$ José Flores Ossorio, obispo de Orihuela.

4.36. 1736, junio, 6 = José Flores Ossorio, obispo de Orihuela.

4.37. 1738, abril, 24 = Alejandro Pérez de Meca, presbítero visitador.

4.38. 1739, junio, 27 = Juan Elías Gómez de Terán, obispo de Orihuela.

4.39. 1742, septiembre, 30 = Juan Elías Gómez de Terán, obispo de Orihuela.

4.40. 1748, octubre, 8 = Juan Elías Gómez de Terán, obispo de Orihuela.

4.41. 1753, septiembre, 2 = Juan Elías Gómez de Terán, obispo de Orihuela.

4.42. 1758 , noviembre, $7=$ Antonio Salvador Navarro, Deán y visitador.

4.43. 1760 , agosto, 24 = Pedro de Albornoz y Tapies, obispo de Orihuela.

4.44. 1766, agosto, 17 = Pedro de Albornoz y Tapies, obispo de Orihuela.

4.45. 1817, marzo, $28=$ Antonio Vidal, vicario y visitador.

4.46. 1826 , julio, 22 = Félix Herrero Valverde, obispo de Orihuela.

4.47. 1832 , julio, $13=$ Félix Herrero Valverde, obispo de Orihuela.

4.48. 1883 , octubre, 23 = Victoriano Guisasola y Rodríguez, obispo de Orihuela.

4.49. 1927, noviembre, 20 = Francisco Javier Irastorza y Loinaz, obispo de Orihuela. 


\begin{tabular}{|c|c|c|c|}
\hline 1. 1567 & 40. 1670 & 79. 1743 & 117. 1800 \\
\hline 2. 1572 & 41. 1671 & 80. 1744 & 118. 1801 \\
\hline 3. $1582,84,85$ & 42. 1672 & 81. 1745 & 119. 1803 \\
\hline 4. 1591 & 43. 1673 & 82. 1746 & 120. 1804 \\
\hline 5. 1596 & 44. 1675 & 83. 1747 & 121. 1805 \\
\hline 6. 1605 & 45. 1677 & 84. 1748 & 122. 1807 \\
\hline 7. 1606 & 46. 1682 & 85. 1749 & 123. 1808 \\
\hline 8. 1607 & 47. 1684 & 86. 1750 & 124. 1809 \\
\hline 9. $1608-11$ & 48. 1689 & 87. 1752 & 125. 1810 \\
\hline 10. 1612 & 49. 1690 & 88. 1754 & 126. 1812 \\
\hline 11. 1618 & 50. 1691 & 89. 1755 & 127. 1813 \\
\hline 12. 1621 & 51. 1692 & 90.1756 & 128. 1815 \\
\hline 13. 1623 & 52. 1693 & 91. 1757 & 129. 1816 \\
\hline 14. 1625 & 53. 1695 & 92. 1759 & 130. 1817 \\
\hline 15. 1626 & 54. 1696 & 93. 1762 & 131. 1819 \\
\hline 16. 1630 & 55. 1698. & 94. 1763 & 132. 1820 \\
\hline 17. 1632 & 56. 1699 & 95. 1764 & 133. 1821 \\
\hline 18. 1634 & 57. 1700 & 96. 1765 & 134. 1823 \\
\hline 19. 1636 & 58. 1702 & 97. 1766 & 135. 1824 \\
\hline 20. 1637 & 59. 1703 & 98. 1767 & 136. 1826 \\
\hline 21. 1640 & 60. 1708 & 99. 1768 & 137. 1828 \\
\hline 22. 1641 & 61. 1709 & 100. 1770 & 138. 1829 \\
\hline 23. 1644 & 62. 1710 & 101. 1772 & 139. 1830 \\
\hline 24. 1645 & 63. 1712 & 102. 1775 & 140. 1835 \\
\hline 25. 1646 & 64. 1713 & 103. 1777 & 141. 1836 \\
\hline 26. 1649 & 65. 1714 & 104. 1779 & 142. 1837 \\
\hline 27. 1653 & 66. 1718 & 105. 1781 & 143. 1839 \\
\hline 28. 1654 & 67. 1719 & 106. 1782 & 144. 1843 \\
\hline 29. 1655 & 68. 1720 & 107. 1784 & 145. 1845 \\
\hline 30. 1657 & 69. 1721 & 108. 1785 & 146. $1854-55$ \\
\hline 31. 1658 & 70. 1723 & 109. 1786 & 147. 1863 \\
\hline 32. 1659 & 71. 1727 & 110. 1788 & 148. 1864 \\
\hline 33. 1660 & 72. 1728 & 111. 1791 & 149. 1865 \\
\hline 34. 1662 & 73. 1730 & 112. 1792 & 150. 1869 \\
\hline 35. 1665 & 74. 1743 & 113. 1793 & 151. 1871 \\
\hline 36. 1666 & 75. 1737 & 114. 1794 & 152. 1889 \\
\hline 37. 1667 & 76. 1738 & 115. 1796 & 153. 1903 \\
\hline 38. 1668 & 77. 1740 & 116. 1797 & 154. $1926,30-36$ \\
\hline 39. 1669 & 78. 1742 & & \\
\hline
\end{tabular}


156. Racional de misas aplicadas en cumplimiento de cargas de la capellanía de San Miguel Arcángel, fundada en la iglesia de Santo Domingo de Ayora por el matrimonio de D. Juan Vicente Piera del Campo y Ana M. a Martínez Avila (19261936).

157. Caja conteniendo trozos de racionales sin fecha.

158. Caja conteniendo trozos de racionales del siglo $X V I$ $(1539$ - 1560 - 1561 - 1562 - 1566 - 1569 - 1573 - 1574 - 1578 1588 - 1592).

159. Caja conteniendo trozos de racionales del siglo XVII (16041605 - 1623 - 1631 - 1633 - 1634 - 1635 - 1636 - 1637 - $1638-$ $1639-1640-1642-1645-1646-1647-1655-1657-1662-$ $1663-1664-1670-1676-1680-1681-1683-1686)$.

160. Caja conteniendo trozos de racionales del siglo XVIII-XIX (1708 1712 - 1715 - 1716 - 1717 - 1722 - 1725 - 1726 - 1732 - 1757 $1761-1762-1840-1860-1861-1868-1870-1880-1881-$ 1882 - $1883-1884-1885-1886-1887-1888-1890-1891-$ $1892-1893-1894-1898-1904-1909)$.

\section{V) LIBROS DE COFRADIAS Y ASOCIACIONES PIADOSAS}

1. Indice de hermanos de la Hermandad de los Santos Mártires San Abdón y San Senén (Altar en la ermita de $\mathrm{Ntr}^{\mathrm{a}} \mathrm{Sr}^{\mathrm{a}}$ del Rosario). 1704. 1 hoja suelta.

2. Libro de la Cofradía del Santísimo Sacramento de Ayora: Incluye cuentas, miembros y obligaciones de los cofrades (1817-1893). 55 fol. in fol., sin foliar. Cubiertas en pergamino con broche.

3. Libro de la Cofradía del Dulce nombre de Jesús del convento de Dominicos de Ayora: Incluye obligaciones de los cofrades, estatutos, nombramiento de mayordomos, listas de cofrades (18501862) y cuentas de la cofradía (1825-1834). Faltan las primeras hojas. Cubiertas en pergamino.

4. Libro de la Cofradia del Corpus de Ayora (1943-1966). Cuentas, cargos, derechos, cofrades y reglamento.

5. Registro de Asociaciones Piadosas de Ayora conforme al elenco número VI de la Santa Visita para 1923 y 1924 . Menciona las siguientes asociaciones:

- Sagrado Corazón de Jesús -Apostolado-: Fundada en 1886.

- Hijas de Maria -Cofradía-: Fundada en 1917.

- San Francisco de Asís -Orden tercera- 1914. 
- Nuestra Sra del Carmen -Cofradía- 1919.

1 folio doble.

6. Libro de la Cofradía del Señor, de Ayora (1944-1954).

7. Libro de la conferencia de San Vicente de Paul. Actas y Cuentas:
7.1. 1948-1954
7.2. $1955-1959$
7.3. $1959-1961$

8. Libro de socios de la conferencia de San Vicente de Paul (1948-1961).

9. Libro de Actas de la Asociación Católica de caballeros (1955-1960).

10. Libro de Actas de las Conferencias parroquiales:
10.1. 1946-1952
10.2. $1953-1963$

11. Libro de la Cofradía de Nuestra Señora de los Desamparados con cuentas del culto, inventario de alhajas, ropas, entradas y salidas (1792-1919). 55 fol. in fol., sin foliar. Cubiertas en pergamino.

\section{VI) LIBROS E INVENTARIOS DE ERMITAS Y DE LA IGLESIA PARRO- QUIAL (72)}

1. Libro y memorial de cuenta y razón de todas las limosnas, gastos, ropa y alhajas de la Virgen del Rosario (1701-1859). 165 fol. in fol., foliado. Cubiertas en pergamino. Contiene un documento del siglo XVI.

2. Inventario de la ermita de Nuestra Señora del Rosario (incluye también gastos y ganancias de la ermita) 1816-1818. 7 fol. in fol.

3. Relación clara y exacta de la ermita de $\mathrm{Ntr}^{\mathrm{a}} \mathrm{Sr}^{\mathrm{a}}$ del Rosario de la villa de Ayora conforme al elenco número Il de la Santa Visita (1924). 4 fol. in fol.

4. Libro de cuentas e inventario de alhajas de la ermita de Santa Bárbara, gastos en obras... (1769-1863). 51 fol. in 1/4. Sin foliar. Cubiertas pergamino.

5. Inventario de la Iglesia parroquial de $\mathrm{Ntr}^{\mathrm{a}} \mathrm{Sr}^{\mathrm{a}}$ de la Asunción y de las iglesias y ermitas enclavadas en Ayora (1918). Las ermitas mencionadas son: Santa Lucia, San Antonio Abad, Virgen del Rosario, San José, Santo Hospital, Santa Ana o iglesia antigua, Santo Angel, Santa Bárbara y Santo Domingo. Incluye datos de 1923-28 al final y un inventario breve del archivo.

6. Relación clara, sucinta y exacta de la iglesia parroquial de Ntra $\mathrm{Sr}^{\mathrm{a}}$ de la Asunción de la villa de Ayora conforme al elenco número I y II del cuestionario para la Visita canónica. 1924. Este inventario al igual que el resto de las mismas fechas fueron realizados por el párroco $D$. Antonio Lledó, quien realizó también un buen trabajo de archivo.

(72) Los inventarios de ermitas, iglesia parroquial y archivo forman cuadernos aparte agrupados en una caja, la mayor parte de ellos son complemento de las Visitas Pastorales, dado que asf lo exigen las mismas. Conviene destacar también que en los libros de visitas se encuentran inventarios de las ermitas, iglesias y menciones a los libros del archivo. 
7. Inventario de la iglesia parroquial de $\mathrm{Ntr}^{\mathrm{a}} \mathrm{Sr}^{\mathrm{a}}$ de la Asunción de Ayora. 1946.

8. Inventario de los efectos y ropa de la capilla de $\mathrm{Ntr}^{\mathrm{a}} \mathrm{Sr}^{\mathrm{a}}$ de la Asunción del Santo Hospital de la Villa de Ayora. 2 copias sin fecha. 4 fol. in fol.

9. Relación clara, sucinta y exacta de la capilla de $\mathrm{Ntr}^{\mathrm{a}} \mathrm{Sr}^{\mathrm{a}}$ de la Asunción del Santo Hospital de la villa de Ayora, conforme al elenco número II del cuestionario para la visita canónica, siendo capellán de esta $D$. Eufrosino Martínez Azorín, 1924. 2 fol. in fol.

10. Inventario de la ermita de San Sebastián. 1648. 3 fol. in fol.

11. Relación clara, sucinta y exacta de la primitiva iglesia de Santa Ana de la villa de Ayora conforme al elenco número II del cuestionario para la Visita canónica. 1924. 2 fol. in fol.

12. Relación clara, sucinta y exacta de la iglesia de Santo Domingo del ex-convento de P.P. Dominicos de la villa de Ayora conforme al elenco número II del cuestionario para la Visita Canónica. 1924.

13. Relación clara, sucinta y exacta de la ermita de San José de la villa de Ayora, conforme al elenco número II del cuestionario para la visita canónica. 1924.

14. Inventario de la ermita de San Antonio Abad. 1924.

15. Inventario de la ermita del Santo Angel. 1924.

16. Inventario de la ermita de Santa Lucía. 1924.

17. Relación de conferencias y casos tratados, celebradas en la sacristía de la parroquial de Ayora (1866).

\section{VII) INVENTARIOS DEL ARCHIVO}

1. 1732 (Abecedario o inventario de los libros, procesos y demás papeles que se hallan en el archivo en el año...). Este inventario se halla entre las primeras páginas del libro de Noticias sueltas número IV. 10 fol. in fol. Una fotocopia de este documento se ha depositado en la caja de inventarios.

2. Inventario de los libros parroquiales que los archiveros y síndicos han entregado al cura de Ayora por mandato del obispo de Orihuela D. Félix Herrero Valverde. 1852. 3 copias de 2 fol. in fol. Este inventario incluye solamente los libros sacramentales.

3. Inventario del archivo parroquial de $\mathrm{Ntr}^{\mathrm{a}} \mathrm{Sr}^{\mathrm{a}}$ de la Asunción de Ayora. 1962. Este inventario realizado por D. Vicente Pastor, cura de esta parroquia es el más completo que se conserva, se extiende a todas las series del archivo, aunque sin una ordenación exacta. 10 fol. in fol. 
VIII) LIBROS DE CULTO PARROQUIAL

1. MANOS O MEMORIAS DE MISAS

\begin{tabular}{|c|c|c|c|}
\hline 1.1. 1627 & 1.18. 1716 & 1.35. 1751 & 1.52. 1796 \\
\hline 1.2. 1630 & 1.19. 1718 & 1.36. 1752 & 1.53. 1797 \\
\hline 1.3. 1631 & 1.20. 1719 & 1.37. 1756 & 1.54. 1799 \\
\hline 1.4. 1642 & 1.21. 1720 & 1.38. 1757 & 1.55. 1802 \\
\hline 1.5. 1655 & 1.22. 1723 & 1.39. 1758 & 1.56. 1803 \\
\hline 1.6. 1670 & 1.23. 1725 & 1.40. 1761 & 1.57. 1809 \\
\hline 1.7. 1672 & 1.24. 1727 & 1.41. 1763 & 1.58. 1810 \\
\hline 1.8. 1678 & 1.25. 1730 & 1.42. 1765 & 1.59. 1812 \\
\hline 1.9. 1679 & 1.26. 1731 & 1.43. 1774 & 1.60. 1813 \\
\hline 1.10. 1680 & 1.27. 1735 & 1.44. 1775 & 1.61. 1816 \\
\hline 1.11. 1683 & 1.28. 1737 & 1.45. 1779 & 1.62. 1820 \\
\hline 1.12. 1686 & 1.29. 1738 & 1.46. 1781 & 1.63. 1821 \\
\hline 1.13. 1688 & 1.30. 1739 & 1.47. 1784 & 1.64. 1825 \\
\hline 1.14. 1702 & 1.31. 1741 & 1.48. 1786 & 1.65. 1826 \\
\hline 1.15. 1703 & 1.32. 1743 & 1.49. 1790 & 1.66. 1832 \\
\hline 1.16. 1713 & 1.33. 1744 & 1.50. 1791 & 1.67. 1841 \\
\hline 1.17. 1715 & $1.34 \cdot 1745$ & 1.51. 1792 & \\
\hline
\end{tabular}

1.68. Caja con las manos que no han sido datadas por carecer de año.

2. LIBROS DE MISAS O MINUTARIOS DE CULTO

\begin{tabular}{|c|c|c|c|}
\hline 2.1. 1709 & 2.20. 1775 & 2.39. 1803 & 2.58. 1837 \\
\hline 2.2. 1710 & 2.21. 1776 & 2.40. 1803 & 2.59. 1837 \\
\hline 2.3. 1719 & 2.22. 1778 & 2.41. 1804 & 2.60. 1838 \\
\hline 2.4. 1719 & 2.23. 1779 & 2.42. 1806 & 2.61. 1840 \\
\hline 2.5. 1724 & 2.24. 1780 & 2.43. 1808 & 2.62. 1845 \\
\hline 2.6. 1731 & 2.25. 1781 & 2.44. 1809 & 2.63. 1850 \\
\hline 2.7. 1736 & 2.26. 1782 & 2.45. 1812 & 2.64. 1857 \\
\hline 2.8. 1737 & 2.27. 1785 & 2.46. 1813 & 2.65. 1858 \\
\hline 2.9. 1741 & 2.28. 1786 & 2.47. 1814 & 2.66. 185 \\
\hline 2.10. 1757 & 2.29. 1787 & 2.48. 1815 & 2.67. 1860 \\
\hline 2.11. 1758 & 2.30. 1791 & 2.49. 1817 & 2.68. 1861 \\
\hline 2.12. 1763 & 2.31. 1792 & 2.50. 1820 & 2.69. 1862 \\
\hline 2.13. 1765 & 2.32. 1794 & 2.51. 1821 & 2.70. 1863 \\
\hline 2.14. 1767 & 2.33. 1795 & 2.52. 1823 & 2.71. 186 \\
\hline 2.15. 1770 & 2.34. 1796 & 2.53. 1825 & 2.72. 186 \\
\hline 2.16. 1771 & 2.35. 1798 & 2.54. 1828 & 2.73. 186 \\
\hline 2.17. 1772 & 2.36. 1799 & 2.55. 1832 & 2.74. 186 \\
\hline 2.18. 1773 & 2.37. 1800 & 2.56. 1834 & 2.75 .186 \\
\hline 2.19. 1774 & 2.38. 1801 & 2.57. 1835 & 2.76. 187 \\
\hline
\end{tabular}


2.77-2.96. Existen además 19 libros que no contienen fecha por faltarle las primeras hojas. La mayoría tienen cubiertas de pergamino, algunas de las hojas de libros de coro.

3. LIBROS ANUALES DE MISAS, ANIVERSARIOS, FESTIVIDADES Y CAPELLANIAS

3.1. Libro de aniversarios de misas rezadas (1611-1730). 256 fol. in fol., sin cubiertas. Faltan las primeras hojas.

3.2. Libro de festividades y aniversarios (1611-1666). 526 fol. in fol. Faltan las 98 primeras hojas y las últimas. Sin cubiertas.

3.3. Libro de anuales de misas, de festividades enteras, medias y... (1678-1725). 916 fol. in fol. Cubiertas en pergamino.

3.4. Libro de aniversarios rezados y cantados (1736-1781). 204 fol. in fol. Cubiertas en pergamino.

3.5. Libro de misas, capellanías, festividades, fábrica menor y otras celebraciones (1722-1799). Al final del libro existen redactados unos acuerdos con el obispo de Orihuela y estatutos para el gobierno de la parroquia de Ayora (1699). 356 fol. in fol. Cubiertas pergamino. En el dorso de las cubiertas se lee: GUION.

3.6. Misas de capellanías y horas de particulares (1732-...).

3.7. Memoria de capellanías fundadas e instituidas en la iglesia de Ayora y de los capellanes obligados desde 1597. Cuaderno sin cubiertas.

3.8. Capellanías que están a cargo del clero de Ayora y otros particulares; doblas que se cantan, medias festividades, conventuales, aniversarios... (1795-...). Cubiertas pergamino.

\section{IX) BENEFICIOS, FUNDACIONES Y OBRAS PIAS}

1. OBRA PIA DE MOSSEN MARTIN PASTORO DE LOS PASTORES:

1.1. Cuentas que $D$..., presbitero de Ayora como patrono y patrono y administrador de la obra Pía fundada por mossen Martín Pastor con destino a auxiliar estudiantes y otras obras de caridad, presenta por el cobro de la inscripción nominativa de la deuda perpetua interior con interés del $4,5 \%$ para los años 1885-1896. Distintos cuadernos.

1.2. Libro de la administración del Rev. Mossen Martín Pastor (1536-1751). 198 fol. in fol. Incluye censos.

1.3. Inventario, apeo y deslinde general de las tierras de la administración de Mossen Martín Pastor. 1752.

1.4. Libro de las entradas de los granos pertenecientes a la obra 
pía fundada por Mossen Martín Pastor (1767-1869). 215 fol. in fol.

1.5. Cuentas de la Administración de los Pastores (1757-60, 1766).

Caja 1

1.6. Cuentas dadas por los administradores de la obra pía de Mossen Martín Pastor (1772 - 73-74-75-77 - 1806-7-8-17-2021-22-23-24 - 25-26-28-29 - 30-31-32-33-34-35 - 36-37-38-39 40-42-45-46 - 48-49-50-51 - 58-59-61-62-66). Distintos cuadernillos.

Caja 2

1.7. Libro de la administración de Mossen Martín Pastor (18711916).

1.8. Cuentas de la administración de Mossen Martín Pastor (1872-73 - 77-79-80-81 - 82-86-87-88-89 - 90-91-92-93-94 95-96-97-98 - 99-1917-18-19-20-21-22-23-27). En cuadernos.

1.9. Libro de la administración de Mossen Martín Pastor (19171962).

1.10. Libro de la administración de Mossen Martín Pastor (19241933).

1.11. Libro de la administración de Mossen Martín Pastor (19331957).

1.12. Pagarés y certificaciones académicas relacionadas con la obra pía de Mossen Martín Pastor (s. XIX-XX).

Caja 3

2. Cuentas de los beneficios de D. a Serafina Rovira de San Juan Bautista y de D. Baltasar de Nieves de la ermita del Rosario (1917-1940).

3. Cuentas de distintos beneficios, obras pías y capellanias (19401956).

4. Libro de la administración de la obra pía fundada por D. Joaquín Ruiz de Assin para celebrar todos los años un septenario a la Virgen de los Dolores (1810-1956).

5. Estado de las memorias, patronatos y obras pías (s. XIX).

6. Capellanias y Fundaciones (s. XIX). 
7. Relación de los beneficios, cepellanías, memorias, mandas y legados piadosos pertenecientes a la iglesia parroquial de Ayora (1924-1960).

8. Legado piadoso de Mossen Agustín del Campo Teruel (1872-1936).

9. Cuentas de administración de los bienes llamados de beneficencia que el señor administrador y presidente de la conferencia de San Vicente de Paúl de Ayora presenta para su aprobación al consejo de dicha institución de caridad, siendo su fundador Pascual María Alonso (1919-1928).

10. Cuentas del beneficio de San Brandano (1957-58).

11. Catálogo de las fundaciones piadosas de Ayora (1867). 2 fol. in fol.

Caja 4

12. Inventario de beneficios (s. XIX). 1 fol. doble. El presente inventario está junto con los inventarios de ermitas y archivos.

13. Libro de Caja del secretariado de caridad de Ayora (1956-1967).

14. Libro de adoptados del secretariado de Caridad de Ayora (19561958).

X) CUADERNOS DE SENSOS Y RENTAS, «libros de censos y rentas del Clero de Ayora que debe cobrar su colector».
1. 1663
15. 1721
29. 1758
43. 1784
2. 1680
16. 1724
30. 1760
44. 1785
3. 1681
17. 1728
31. 1763
45. 1786
4. 1683
18. 1734
32. 1764
46. 1790
5. 1689
19. 1735
33. 1765
47. 1792
6. 1691
20. 1737
34. 1766
48. 1798
7. 1710
21. 1740
35. 1768
49. 1801
8. 1712
22. 1742
36. 1771
9. 1713
23. 1743
37. 1775
50. 1809
10. 1714
24. 1748
38. 1776
51. 1810
11. 1716
25. 1749
39. 1779
52. 1816
12. 1717
26. 1751
40. 1781
53. 1838
13. 1718
27. 1752
41. 1782
54. 1839
14. 1719
28. 1754
42. 1783
55. 1840
56. 1860 
XI) CUENTAS DE LAS COLECTAS DEL CLERO, hechas por el colector ("Cuentas de ordinarios, capsueldos, natumortis, derechos de sepultura... censos y rentas). En cuadernos.

\begin{tabular}{|c|c|c|c|}
\hline 1. 1558 & 13. 1611 & 25. 1643 & 36. 166 \\
\hline 2. 1594 & 14. 1613 & 26. 1645 & 37. 1663 \\
\hline 3. 1595 & 15. 1616 & 27. 1647 & 38. 1664 \\
\hline 4. 1596 & 16. 1619 & 28. 1648 & 39. 1689 \\
\hline 5. 1597 & 17. 1620 & 29. 1650 & 40. 1690 \\
\hline 6. 1598 & 18. 1621 & 30. 1652 & 41. 1691 \\
\hline 7. 1599 & 19. 1626 & 31. 1653 & 42. 1692 \\
\hline 8. 1602 & 20. 1629 & 32. 1654 & 43. 1693 \\
\hline 9. 1603 & 21. 1630 & 33. 1655 & 44. 1694 \\
\hline 10. 1604 & 22. 1638 & 34. 1656 & 45. 1695 \\
\hline 11. 1606 & 23. 1639 & 35. 1661 & 46. 1696 \\
\hline 12. 1610 & 24. 1640 & & \\
\hline
\end{tabular}

\section{XII) OTROS LIBROS DE CUENTAS Y CENSOS}

1. Noticia del agua que posee el clero de Ayora con los días de tanda, órdenes, número sujetos, de quienes las compro y sus escrituras. 1841.

2. Libro de las propiedades de los censos que se quitan y de nuevo se entregan al Clero para diversas obras pías que se depositan en el archivo hasta hacerse nuevo cargamiento (1618-1662). 160 fol. in fol. Cubiertas pergamino.

3. Reducción de censos (1621). Cuaderno.

4. Libro de los títulos de los censos de Ayora (1684-...). Sin cubiertas.

5. Libro para formar las cuentas de administración de las limosnas que dan los fieles a las almas del Purgatorio (1807-1896). Cubiertas pergamino.

6. Libro de cuenta y razón de Pedro Pascual Pí con diferentes personas de esta villa y forasteros (1819-1870). $30 \mathrm{fol}$. in fol. Cubiertas pergamino. 
7. Fincas del Clero de la parroquia de Ayora hasta 1841, poseídas en el término de Alpera. Otra relación de fincas del clero (1832-34).

\section{XIII) CABREUS DE CENSOS Y CENSALS}

1. Cabreu de los censales de aniversarios y misas del clero de Ayora (1526-1534), compuesto por Johan Orti, notario público. 341 fol. in fol. doble ( $33 \times 24 \mathrm{~cm}$.), foliados. Encuadernación pergamino. "L/ibre primer" y en el dorso la voz "Cabreus".

2. Cabreu de los censales de aniversarios y misas del clero de Ayora (1534-1547), compuesto por Johan Orti, notario. 294 fol. in fol. doble, foliado. Cubiertas pergamino. Lleva en el dorso la voz: "Cabreus, llibre segon". En el folio $241 r^{\circ}$ se lee: "Cabreu e memorial d'els censals de les llumenarres del Sant Sacrament del altar axi per a olli a la llantia de aquell com encara per a ciris per acompanyar lo Sant Sacrament e son los seguents...".

3. Cabreu i cargaments (1600-1651). Jaime lbáñez, notario. 837 fol. in fol. doble $(42 \times 30 \mathrm{~cm}$.). Sin cubiertas y con primeras hojas en mal estado.

4. Cabreus de los vecinos de la villa de Cofrentes del año 1675 , recibido por Miguel Juan de Alcaraz, notario público. Cuaderno con 40 fol. in fol.

5. Cabreu con los vecinos de la villa de Xalance (sic. Jalance) del año 1675, recibido por Miguel Juan de Alcaraz, notario público. Cuaderno con 60 fol. in fol.

6. y 7. Cabreus de los vecinos de la villa de Xarafuel (sic. Jarafuel) del año 1675, recibidos por Miguel Juan de Alcaraz, notario público. 2 cuadernos de 98 y $70 \mathrm{fol}$. in fol. respectivamente. El segundo cuaderno contiene también datos sobre las propiedades de algunos vecinos de Ayora, Carcelen y Teresa de Cofrentes.

8. Cabreu de los vecinos de la villa de Zarra del año 1675 , recibido por Miguel Juan de Alcaraz, notario público. Cuaderno de 58 fol. in fol.

9. Cabreu de los vecinos de la villa de Teresa de Cofrentes del año 
1675, recibido por Miguel Juan de Alcaraz, notario público. Cuaderno de 70 fol. in fol.

10. Baldufario de los censos que han cabrevado algunos particulares a favor del reverendo clero de la parroquial de Ayora, comenzando en el año 1678, siendo receptor Francisco Teruel, notario menor. Sin foliar $(23 \times 17 \mathrm{~cm}$.). En el dorso se lee: "Cabreus de Teruel 16751695\%. Cubiertas pergamino.

11. Libro de títulos de la parroquia de Ayora (1729- (1734?)1818). 778 fol. in doble fol. $(42 \times 30 \mathrm{~cm}$.).

XIV) FABRICA PARROQUIAL. A pesar de que en anteriores inventarios se hace mención a varios libros de fábrica, nada queda de ellos salvo algunas hojas y cuadernillos sueltos, que consignamos a continuación:

1. Nombramiento de fabriquero y otros asuntos de fábrica (1810). 8 fol. in fol.

2. Gastos de la obra de la parroquial de Ayora (1845-46-47).

3. Cuentas de los ingresos y gastos en el blanqueo, ornato y construcción del retablo de la capilla de la Comunión (1854)). 2 fol. in fol.

4. Continuación de las obras de fábrica de la parroquial de Ayora (1860-68). Cuaderno.

5. Cuentas de la obra de reparación de la casa abadia (1861).

6. Libretas de cuentas de culto y fábrica de la Iglesia parroquial de Ayora:

\section{1. $1866-1954 \quad 6.2 .1954-1978$}

7. Acta de bendición de la ermita reedificada de Santa Bárbara (Ayora) y autorización del prelado diocesano para la venta del solar sobrante. Incluye relación detallada de la inversión, importe, gastos de reconstrucción y plano de la ermita (1923). 5 fol. in fol. +3 fol. in 1/2 fol. + 1 plano.

8. Relación detallada de la inversión de 1.000 pesetas en la íglesia de 
Santo Domingo de Ayora, procedentes del legado piadoso de D. Facundo Rogla a favor de la misma (1925). 2 fol. in fol. + recibos.

9. Testimonio de la erección del «Vía crucis» en el camino del cementerio de Ayora (1925). 4 fol. in 1/2 fol.

\section{XV) FONDO DEL HOSPITAL DE AYORA}

\section{CENSOS DEL HOSPITAL:}

1.1. Libro de los censos de la capellanía y patronato que fundó Mossen Miguel Martínez, comisario del Santo Oficio de la inquisición de Murcia, siendo capellán de ésta el presbítero $D$. Marcos Alonso y Galiana (1736-1929). 167 fol. in fol. Cubiertas pergamino. 1.2. Censos cargados sobre la capellanía del Hospital (1777-1862). 1.3. Censos del Santo Hospital de Ayora pertenecientes a 18521864. Cuadernillo. 29 fol. in $1 / 2$ fol.

Caja 1

2. CUENTAS DEL HOSPITAL Y ASILO:

2.1. Libro que contiene el gasto que hacen los pobres enfermos, naturales de Ayora, que vienen al Hospital de Ntr. ${ }^{a}$ Sr. ${ }^{a}$ de la Asunción de la misma, de la renta y demás, que para este efecto dejó el presbitero mossen Miguel Martínez Bolinches, según su último testamento en 11 de noviembre de 1686 (1805-1878). 203 fol. in fol. Cubiertas pergamino.

2.2. Cuentas de la capellanía del Hospital (1805). 2 fol. in fol.

2.3. Cuentas de la capellanía fundada por Mossen Miguel Martinez en el Hospital de Ayora (1833-1845).

2.4. Cuentas del asilo-hospital de Ayora (1859-1927).

2.5. Administración del Santo Hospital y beneficencia (recibos, cuentas...) (1859-1964).

2.6. Libro de la administración de los fondos del Hospital de Ayora, en el que se expresan los nombres de los que tienen tomado dinero de este fondo al interés del $6 \%$ anual, cantidad que tienen recibida y pagos que tienen hechos (1874-1919). 96 fol. in fol. +104 hojas en blanco. Cubiertas cartone.

2.7. Cuentas del legado benéfico de D. Pascual María Alonso para los pobres de Ayora correspondiente a 1918.

2.8. Libro de administración de la capilla y legados piadosos del Hospital de Ayora (Asilo) (1923-1936). 8 págs. in fol. + 92 hojas en blanco. Cubiertas cartone. 
2.9. Cuentas de los bienes del Santo Hospital de Ayora (19281962).

2.10. Cuentas de las obras del Santo Hospital y asilo (1944-1948).

2.11. Cuentas de la administración del Hospital y asilo (1945-1957).

Cajas 2 y 3

3. VARIOS:

3.1. Racional de celebración de misas en la capilla del Santo Hospital por el alma e intenciones del fundador mossen Miguel Martínez (1805-...).

3.2. Racional de misas celebradas en el oratorio del Hospital de Ntr. ${ }^{a} \mathrm{Sr}^{\mathrm{a}}$ de la Asunción por el actual capellán D. Elías García Martínez, en cumplimiento de la Pía fundación que hizo el presbitero Miguel Martínez Bolinches (1805-1932). 51 fol. in fol. + 105 hojas en blanco. Cubiertas pergamino.

3.3. Inventario del asilo (1957), incluye libros de censos del Hospital (1878) y de gastos de los enfermos.

3.4. Copia del testamento de D. Eduardo López Caviro (1922, septiembre, 14).

3.5. Junta de beneficencia del Hospital. Circulares y cartas (19431960).

3.6. Donación por parte del ayuntamiento de Ayora del solar del antiguo convento Dominico a la Iglesia para hospital y asilo. Ante José Andrés Herrero de Lara, notario (1948, abril, 3).

3.7. Acuerdos entre la Junta de beneficencia del asilo y las Hermanas de San José (1958).

3.8. Inventario de los documentos pertenecientes a la administración de beneficencia que $D$. José del Campo hace entrega...

3.9. Varias recetas médicas (s. XIX).

Caja 4

XVI) CENSOS O PADRONES PARROQUIALES DE POBLACION
1. $1853-57$
3. $1870-79$
5. $1890-99$
7. Sin fecha
2. $1857-68$
4. $1880-89$
6. $1900-24$

XVII) BULAS DE INDULGENCIAS PLENARIAS, concedidas por varios Papas a particulares de la villa de Ayora en número de 63 de los años 1682-1757. 
XVIII) DECRETOS, PASTORALES, ORDENES, CIRCULARES Y CORRESPONDENCIA DEL OBISPADO DE ORIHUELA CON LA PARROQUIA DE AYORA (S. XVIII-XX).

\section{XIX) LIBROS DE CLAUSULAS TESTAMENTALES}

1. 1583-1820. Indice de Cláusulas Testamentales. 106 fol. in fol. (foliado). Cub. perg.

2. 1583-1602. Libro de Cláusulas Testamentales. 288 fol. in fol., foliado. Cubiertas perg:

3. 1603-1626. Libro de Cláusulas Testamentales. 387 fol. in fol. Cubiertas pergamino.

4. 1626-1640. Libro de Cláusulas Testamentales. 414 fol. in fol. Cubiertas pergamino.

5. 1640-1660. Libro de Cláusulas Testamentales. 310 fol. in fol. Cubiertas pergamino.

6. 1660-1685. Libro de Cláusulas Testamentales. 482. fol. in fol. Cubiertas pergamino.

7. 1686-1723. Libro de Cláusulas Testamentales. 567 fol. in fol. Cubiertas pergamino.

8. 1724-1748. Libro de Cláusulas Testamentales. 331. fol. in fol. Cubiertas pergamino.

9. 1749-1767. Libro de Cláusulas Testamentales. 390 fol. in fol. Cubiertas pergamino.

10. 1768-1781. Libro de Cláusulas Testamentales. 282 fol. in fol. Cubiertas pergamino.

11. 1781-1795. Libro de Cláusulas Testamentales. 277 fol. in fol. Cubiertas pergamino.

12. 1796-1807. Libro de Cláusulas Testamentales. 213. fol. in fol. Cubiertas pergamino.

13. 1807-1820. Libro de Cláusulas Testamentales. 181 fol. in fol. Cubiertas pergamino.

14. 1820-1843. Libro de Cláusulas Testamentales. 228 fol. in fol. Cubiertas pergamino.

XX) TESTAMENTOS: Como complemento de las cláusulas testamentales y de los Protocolos notariales existen una serie de cuadernillos (18) en tamaño de 1/2 fol. que correspondientes al período 1561-1714 recogen los testamentos de diferentes personas que han legado parte de sus bienes a la parroquia de Ayora. 
XXI) DOCUMENTOS JUDICIALES O PROCESOS (LEGAJOS):

\begin{tabular}{|c|c|c|c|c|c|}
\hline 1. $1680-1711$ & 43 & expedientes & 13. 1753 & 102 & expedientes \\
\hline 2. $1712-1715$ & 47 & " & 14. 1754 & 109 & » \\
\hline 3. $1716-1719$ & 36 & 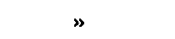 & 15. 1755 & 54 & $》$ \\
\hline 4. $1720-1723$ & 57 & $"$ & 16. $1756-57$ & 51 & ” \\
\hline 5. $1724-1728$ & 23 & $"$ & 17. $1758-62$ & 55 & » \\
\hline 6. $1729-1735$ & 33 & $n$ & 18. $1763-69$ & 21 & $»$ \\
\hline 7. $1736-1742$ & 39 & 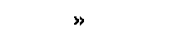 & 19. $1770-79$ & 14 & $"$ \\
\hline 8. $1743-1744$ & 63 & $»$ & 20. $1780-85$ & 22 & $»$ \\
\hline 9. $1745-1746$ & 53 & $"$ & 21. $1786-89$ & 21 & ” \\
\hline 10. $1747-1748$ & 31 & $"$ & 22. $1790-99$ & 12 & $"$ \\
\hline 11. $1749-1750$ & 33 & ” & 23. $1800-3$ & 26 & $"$ \\
\hline 12. 1751-1752 & 105 & $"$ & 24. $1804-60$ & 17 & $"$ \\
\hline
\end{tabular}

25. Cuadernillos de pleitos incompletos.

26. y 27. Procesos y documentos Judiciales incompletos.

\section{XXII) PROTOCOLOS Y MINUTARIOS NOTARIALES}

1. AlCARAZ, Miguel Juan de
1.1. $1662-63(\mathrm{P})$
1.6. $1668(\mathrm{P})$
1.11. $1676-77$ (P) 1.16. $1684-85$ (P)
1.2. $1664(P)$
1.7. 1669-71(P) 1.12. 1677(Inc)
1.17. 1687 (Inc)
1.3. $1665(\mathrm{P})$
1.8. 1672-73(P) 1.13. 1678(P)
1.18. $1688(\operatorname{lnc})$
1.4. $1666(\mathrm{P})$
1.9. 1674-75(P) 1.14. 1679(P)
1.19. $1695(\operatorname{lnc})$
1.5. $1667(P)$
1.10. $1675(\operatorname{lnc})$
1.15. $1680-83(P)$
1.20. 1696 (lnc)

2. CAMPO, Bartolomé del
2.1. $1680(\operatorname{lnc})$

3. CAMPO, Esteban del

3.1. 1715 (Inc-M) 3.3. 1718 (Inc-M) 3.5. $1720($ Inc-M) 3.7. 1722(Inc-M)

3.2. $1717($ Inc-M) 3.4. 1719 (Inc-M) 3.6. 1721(Inc-M) 3.8. 1723(lnc-M)

4. CAMPO, Miguel Antonio del

4.1. 1738-63(Baldufari-índice). 
5. CATALAN XARA, Juan

5.1. 1651-92(Bald) 5.9. 1659(Inc) 5.17. 1669(Inc) 5.24. 1677-81(P)

5.2. $1651-53(P) \quad$ 5.10. $1660(P) \quad$ 5.18. $1670(P) \quad$ 5.25. 1682-83(P)

5.3. 1652(Inc) 5.11. 1660-(Inc) 5.19. 1670(Inc) 5.26. 1684-85(P)

5.4. 1653(Inc) 5.12. 1661(P) 5.20. $1671(\mathrm{lnc}) \quad$ 5.27. 1686(P)

5.5. 1654-56(P) 5.13. 1666(lnc) 5.21. 1673(P) 5.28. 1687(P)

5.6. 1657(lnc) 5.14. 1667(lnc) 5.22. 1674(P) 5.29. 1688(P)

5.7. 1657-59(P) 5.15. 1667-68(Inc)5.23. 1675-76(P) 5.30. 1689-90(P)

5.8. $1658(\mathrm{inc}) \quad$ 5.16. $1668(\mathrm{inc})$

6. ESCRIBA, José

6.1. $1678(\mathrm{lnc})$

7. ESCRIBA, Miguel Juan

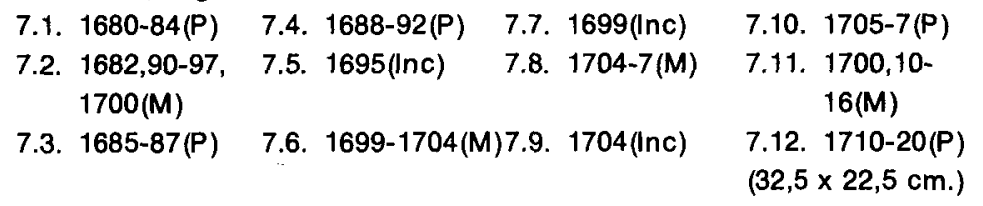

8. GARCIA, José
8.1. $1679(\operatorname{lnc})$
8.6. $1688(\operatorname{lnc})$
8.11. 1694-95(P)
8.15. 1697 (Inc)
8.2. $1679-80(\mathrm{P})$
8.7. 1689-92(P)
8.12. 1694(Inc)
8.16. 1699 (Inc)
(sin cubierta)
8.3. $1681-82(P)$
8.8. 1691 (lnc)
8.13. 1695(lnc)
8.17. 1700 (Inc)
8.4. 1683-84(P)
8.9. 1692(lnc)
8.14. 1695(lnc)
8.18. 1701 (Inc)

8.5. $1685-88(\mathrm{P}) \quad$ 8.10. $1693(\mathrm{lnc})$

9. IBAÑEZ, Juan
9.1. 1619-44
9.3. $1624(M)$
9.5. 1630-35(P)
(Inc-Bald)
9.2. 1622 (Inc-M)
9.4. 1625-29(P)
9.6. $1636-44(P)$

10. IBAÑEZ, Pascual

10.1. 1622-26(P) 10.5. 1634-35(P) 10.9 1638(P) 10.12. 1641-42(P) 10.2. 1627-29(P) 10.6. 1636(P) 10.10. 1639(P) 10.13. 1643-45(P) 10.3. $1630-31(P) \quad$ 10.7. $1636(\mathrm{nc})$ 10.11. 1640(P) 10.14. 1645-50(P) 10.4. 1632-33(P) 10.8. 1637(P)

11. JUAN, Francisco

11.1. 1725(Inc-P) 
12. MARTI, Cristóbal

12.1. 1656 (Inc-P) 12.5. $1678(P) \quad$ 12.9. 1684-85(P) 12.13. 1699 (Inc)

12.2. 1673 (Inc-P) 12.6. $1679-81(P) \quad 12.10 .1688,94, \quad 12.14 .1700-5(P)$ 97-99(P)

12.3. 1675(Inc-P) 12.7. $1682(\mathrm{lnc}) \quad$ 12.11. 1691-96(P) 12.15. 1704(Inc-P) 12.4. $1677(\mathrm{P})(73)$ 12.8. $1683(\mathrm{lnc}) \quad$ 12.12. $1697(\mathrm{Inc}) \quad$ 12.16. 1705 (Inc-P)

13. MARTI, Lorenzo

13.1. $1636-69$ 13.6. $1644(P) \quad$ 13.10. $1651-53,55,13.14 .1665-66(P)$ (Bald)

13.2. 1636-37(P) 13.7. $1645(\mathrm{P}) \quad$ 13.11. $1654(\mathrm{nc}) \quad$ 13.15. 1667-68(P)

13.3. $1638-39(P) \quad$ 13.8. $1646-47(P) \quad 13.12 .1657-58(P)$ 13.16. 1671 (Inc-P)

13.4. $1640-41(P) \quad$ 13.9. $1648-49(P) \quad 13.13 .1663-64(P)$ 13.17. 1672 (Inc-P)

13.5. $1642-43(P)$

14. MARTINEZ, Juan

14.1. 1570 (Inc) 14.14. 1592 (Inc) 14.27. 1609-10(P) 14.40. 1625(Inc) 14.2. 1574-91 14.15. 1593(P) 14.28. 1611 (Inc) 14.41. 1626(Inc) 14.3. $1576-78(\mathrm{P})$ 14.16. $1594(\mathrm{InC}) \quad 14.29 .1612(\mathrm{Inc}) \quad 14.42 .1627(\mathrm{Inc})$ 14.4. $1579(\mathrm{Inc}) \quad 14.17 .1595(\mathrm{P}) \quad$ 14.30. $1613(\mathrm{Inc}) \quad 14.43 .1629(\mathrm{Inc})$ 14.5. $1580(\mathrm{P}) \quad$ 14.18. $1596(\mathrm{InC})$ 14.31. 1614(Inc) 14.44. 1631(Inc) 14.6. $1581(\mathrm{Inc}) \quad 14.19 .1597-98(P)$ 14.32. 1615(Inc) 14.45. 1632(Inc) 14.7. $1582(\mathrm{Inc}) \quad 14.20 .1599(\mathrm{P}) \quad 14.33 .1617(\mathrm{Inc}) \quad 14.46 .1633(\mathrm{Inc})$ 14.8. 1583(P) 14.21. $1600(\mathrm{Inc}) \quad 14.34 .1618(\mathrm{Inc}) \quad 14.47 .1634(\mathrm{Inc})$ 14.9. 1585(P) 14.22. 1601 (nc) 14.35. 1619 (Inc) 14.48. 1636(Inc) $14.10 \quad 1570$ (Inc $\quad 14.23 \quad 1602(\mathrm{Inc}) \quad 14.36 \quad 1620$ (Inc) $14.49 \quad 1637(\mathrm{Inc})$ 14.11. $1587(\mathrm{lnc})$ 14.24. $1603(\mathrm{P}) \quad$ 14.37. 1620-22(P) 14.50. $1638(\mathrm{Inc})$ 14.12. $1590(\mathrm{P})$ 14.25. $1604-5(\mathrm{P})$ 14.38. $1623(\mathrm{Inc})$ 14.51. 1643-44(P) 14.13. $1591(P) \quad 14.26 .1607-8(P) \quad 14.39 .1624(\mathrm{InC})$

15. MARTINEZ BLANCO, Miguel 15.1. $1565(P)$

16. NIEVES, Francisco 16.1. 1752,62-75(Indice y Protocolo).

17. ORTI, Juan Bautista 17.1. $1555-87(P) \quad 17.2 .1584(P) \quad$ 17.3. $1585(P) \quad$ 17.4. $1585-93(P)$ 
18. ORTIZ, Andrés

18.1. 1655 (lnc) $\quad$ 18.4. $1657-58(P) \quad 18.6 .1659(\mathrm{lnc}) \quad 18.81661(\mathrm{P})$

18.2. $1656(\mathrm{lnc}) \quad$ 18.5. $1658(\mathrm{Inc}) \quad$ 18.7. $1661(\mathrm{P}) \quad$ 18.9. 1663 (Inc-P)

18.3. $1655-56(P)$

19. PAVIA, Raimundo

19.1. $1673($ Inc-M)

20. PERALES, Luis

20.1. $1688(\mathrm{Inc}) \quad$ 20.6. $1693(\mathrm{Inc}) \quad 20.11 .1701(\mathrm{nc}) \quad 20.16 .1705(\operatorname{lnc})$

20.2. $1688-89(\mathrm{P}) \quad$ 20.7. $1694(\mathrm{Inc}) \quad 20.12 .1702(\mathrm{InC}) \quad 20.17 .1707(\mathrm{Inc})$

20.3. 1689 (Inc) 20.8. $1695(\mathrm{Inc}) \quad 20.13 .1702-3(\mathrm{P}) \quad 20.18 .1707-12(\mathrm{P})$

20.4. 1689-91(M) 20.9. $1697-1700$ 20.14. 1703(Inc) 20.19. 1711(Inc)

(M)

20.5. $1690-92(P) \quad 20.10 .1699(\operatorname{lnc}) \quad 20.15 . \quad 1704(\operatorname{lnc}) \quad 20.20 .1713(\operatorname{lnc})$

21. PERALES, Nicolás

21.1. $1586(\mathrm{Inc}) \quad$ 21.7. $1604(\mathrm{Inc}) \quad 21.13 .1618(\mathrm{P}) \quad 21.19 .1629(\mathrm{Inc})$

21.2. $1587(\mathrm{lnc}) \quad$ 21.8. $1605(\mathrm{Inc}) \quad 21.14 .1618(\mathrm{Inc}) \quad 21.20 .1634-35(\mathrm{P})$

21.3. $1601(P) \quad$ 21.9. $1606(P) \quad 21.15 .1625(\mathrm{lnc}) \quad 21.21 .1636-37(P)$

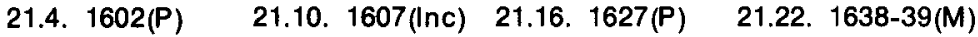

21.5. $1603(\mathrm{P}) \quad$ 21.11. $1609(\mathrm{P}) \quad 21.17 .1627(\mathrm{Inc}) \quad 21.23 .1638-39(\mathrm{P})$

21.6. $1604(P) \quad 21.12 .1613(P) \quad 21.18 .1629(P) \quad 21.24 .1640-43(P)$

22. PUEBLA, Pedro de la

22.1. 1680 (Inc-M) 22.2. 1681 (Inc-M)

23. RICO, Juan Francisco

23.1. $1715-36 \quad$ 23.2. $1715-22(\mathrm{P})$ 23.3. $1729-36(\mathrm{P})$

(Bald) $\quad(32 \times 22,5) \quad(32 \times 22,5)$

24. ROVIRA, Bartolomé

24.1. 1547 (inc-P)

25. ROVIRA, Bartolomé Juan

25.1. $1619-20(P) \quad 25.2$. $1626-28(P)$

26. ROVIRA, Jaime

26.1. $1599-1600$

(Inc-P) 
27. TELLO, Francisco

27.1. $1591(\mathrm{lnc}) \quad$ 27.2. $1604(\mathrm{nnc}) \quad$ 27.3. $1606(\mathrm{Inc}) \quad 27.4 .1607$ (Inc)

28. TERUEL, Francisco

28.1. 1644-45(P) 28.10. $1657-58(P)$ 28.19. $1680(\operatorname{lnc}) \quad 28.27 .1693-94(P)$

28.2. $1647-48(P) \quad 28.11 .1659-60(P)$ 28.20. 1681(Inc) 28.28. 1694-(Inc)

28.3. $1649(\mathrm{P}) \quad$ 28.12. $1661(\mathrm{P}) \quad$ 28.21. 1682(Inc) 28.29. 1695(M)

28.4. 1650(P) 28.13. 1662-63(P) 28.22. 1683-88(P) 28.30. 1695-96(P)

28.5, $1651(\mathrm{P}) \quad$ 28.14. 1664-69(M)28.23. 1687(lnc) 28.31. 1696(lnc)

28.6. 1651 (Inc-M) 28.15. 1666-70(P) 28.24. 1689-92(P) 28.32. $1698(\mathrm{lnc})$

28.7. 1652(Inc-M) 28.16. 1670-74(P) 28.25. 1691(Inc) 28.33. 1699(Inc)

28.8. 1653-54(P) 28.17. 1672-77(P) 28.26. 1692(lnc) 28.34. 1700(Inc)

28.9. 1655-56(P) 28.18. 1678-82(P)

28.35. Existe un minutario-índice para 1666-1698, bajo la tutoría de Francisco Teruel "el menor".

29. XULBE, Juan

29.1. 1649-50(P) 29.2. 1651(P)

30. FORMULARIOS

30.1. (1587-88?) Anónimo. Sin cubiertas (73).

30.2. (1670-72?). Anónimo. Sin cubiertas.

30.3. Formulario en el protocolo de Juan Martínez correspondiente a los años 1574-1591.

XXIII) LIBROS DE NOTICIAS SUELTAS. Libros de documentos cosidos formando tomos de temática variable: censos, gastos, fábrica de órgano, salarios, disposiciones del obispado de Orihuela, procesos... etc. Según el inventario del archivo de 1962 había 11 libros de noticias sueltas, de los que sólo quedan cuatro.

1. 1563-1750. Contiene censos, rentas de misas y aniversarios, cantidades cobradas por cada presbítero, gastos y fábrica del año 1695 y siguientes, ermita de San Sebastián, libro racional de 1650, disposiciones de los obispos de Orihuela, capítulos de constitución y fábrica de órgano (1750). Cubiertas de pergamino y sin foliar.

(73) La frecuencia de documentos del notario público de Ayora Alonso Muñoz parece darlea éste la paternidad. 
2. 1589-1763. Además de lo dicho para el anterior contiene salario del organista (Tomás de Vera en 1611) y visitas Pastorales de 1761-62 y 63. Sin tapas, tiene las primeras hojas en mal estado; sin foliar.

3. Siglos XVI-XVIII. /dem. Cubiertas pergamino; sin foliar.

4. 1600-1756. Además de lo dicho para los anteriores tomos contiene en las primeras páginas un inventario del archivo de 1737.

XXIV) LIBROS VARIOS

1. LIBROS CONSUETA

1.1. Libro consueta de 1924. 2 fol. in fol. Contiene los cultos ordinarios y extraordinarios, así como otras noticias interesantes sobre el clero de Ayora.

1.2. Libro consueta (1954-59). 67 págs. in fol. +123 hojas en blanco. Tapas cartone.

2. LIBRO DE CORO. $150 \mathrm{fol}$. in $56 \times 35,5 \mathrm{~cm}$. Folios en pergamino y cubiertas en piel con refuerzos de hierro. Letra gótica. Contiene 70 iniciales miniadas con motivos vegetales y geométricos distintos. Se inicia con "KIRIE ELEYSON, CHRISTIE ELEYSON» (Misa I. $\left.{ }^{a} \mathrm{Cla}^{\mathrm{e}} 4 .^{\circ} \mathrm{T} .{ }^{\circ}\right)$. Pentagrama (5 líneas).

3. Libro «Satatu Animarum» de la parroquia de Ayora (1946).

4. Catecismo parroquial de Ayora (1958-72).

5. Cuentas del cine parroquial (1956-60).

6. Fondo del Cementerio parroquial de Ayora: Libros de propietarios, recibos...

7. Legado documental de D. Vicente Tormo, presbítero: Incluye sermones y documentación semejante. 